\title{
Estrogen Treatment Reverses Prematurity-Induced Disruption in Cortical Interneuron Population
}

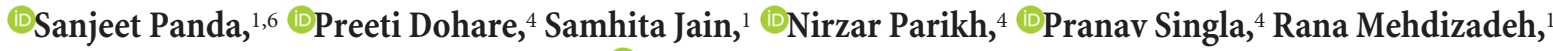 \\ Damon W. Klebe, ${ }^{4}$ George M. Kleinman, ${ }^{3}{ }^{-}$Bokun Cheng, ${ }^{4}$ and Praveen Ballabh ${ }^{1,2,4,5}$ \\ ${ }^{1}$ Department of Pediatrics, ${ }^{2}$ Department of Cell Biology and Anatomy, ${ }^{3}$ Department of Pathology, Maria Fareri Children's Hospital, New York Medical \\ College, Valhalla, New York 10595, ${ }^{4}$ Department of Pediatrics and Dominick P. Purpura Department of Neuroscience, ${ }^{5}$ Children's Hospital, Montefiore- \\ Albert Einstein College of Medicine, Bronx, New York 10461, and 'Department of Pediatrics, Texas Tech University of Health Sciences, El Paso, Texas 79905
}

Development of cortical interneurons continues until the end of human pregnancy. Premature birth deprives the newborns from the supply of maternal estrogen and a secure intrauterine environment. Indeed, preterm infants suffer from neurobehavioral disorders. This can result from both preterm birth and associated postnatal complications, which might disrupt recruitment and maturation of cortical interneurons. We hypothesized that interneuron subtypes, including parvalbumin-positive $\left(\mathrm{PV}^{+}\right)$, somatostatin-positive $\left(\mathrm{SST}^{+}\right)$, calretinin-positive $\left(\mathrm{CalR}^{+}\right)$, and neuropeptide $\mathrm{Y}$-positive $\left(\mathrm{NPY}^{+}\right)$interneurons, were recruited in the upper and lower cortical layers in a distinct manner with advancing gestational age. In addition, preterm birth would disrupt the heterogeneity of cortical interneurons, which might be reversed by estrogen treatment. These hypotheses were tested by analyzing autopsy samples from premature infants and evaluating the effect of estrogen supplementation in prematurely delivered rabbits. The $\mathrm{PV}^{+}$and CalR ${ }^{+}$neurons were abundant, whereas SST ${ }^{+}$and NPY ${ }^{+}$neurons were few in cortical layers of preterm human infants. Premature birth of infants reduced the density of $\mathrm{PV}^{+}$or $\mathrm{GAD}^{+}{ }^{+}$neurons and increased SST ${ }^{+}$interneurons in the upper cortical layers. Importantly, $17 \beta$-estradiol treatment in preterm rabbits increased the number of $\mathrm{PV}^{+}$neurons in the upper cortical layers relative to controls at postnatal day 14 (P14) and $\mathrm{P} 21$ and transiently reduced SST population at P14. Moreover, protein and mRNA levels of Arx, a key regulator of cortical interneuron maturation and migration, were higher in estrogen-treated rabbits relative to controls. Therefore, deficits in $\mathrm{PV}^{+}$and excess of SST $^{+}$ neurons in premature newborns are ameliorated by estrogen replacement, which can be attributed to elevated Arx levels. Estrogen replacement might enhance neurodevelopmental outcomes in extremely preterm infants.

Key words: Arx; cerebral cortex; estrogen; interneuron; parvalbumin; somatostatin

Significance Statement

Premature birth often leads to neurodevelopmental delays and behavioral disorders, which may be ascribed to disturbances in the development and maturation of cortical interneurons. Here, we show that preterm birth in humans is associated with reduced population of parvalbumin-positive $\left(\mathrm{PV}^{+}\right)$neurons and an excess of somatostatin-expressing interneurons in the cerebral cortex. More importantly, $17 \beta$-estradiol treatment increased the number of $\mathrm{PV}^{+}$neurons in preterm-born rabbits, which appears to be mediated by an elevation in the expression of Arx transcription factor. Hence the present study highlights prematurity-induced reduction in $\mathrm{PV}^{+}$neurons in human infants and reversal in their population by estrogen replacement in preterm rabbits. Because preterm birth drops plasma estrogen level 100-fold, estrogen replacement in extremely preterm infants might improve their developmental outcome and minimize neurobehavioral disorders.

\section{Introduction}

Preterm-born children often exhibit neurodevelopmental delays and behavioral disorders (Anderson et al., 2003; Delobel-Ayoub

Received Feb. 17, 2018; revised May 22, 2018; accepted June 17, 2018.

Author contributions: S.P., D.W.K., B.C., and P.B. edited the paper; P.B. wrote the first draft of the paper; P.B. designed research; S.P., P.D., S.J., N.P., P.S., R.M., D.W.K., B.C., and P.B. performed research; G.M.K. contributed unpublished reagents/analytic tools; P.B. analyzed data; P.B. wrote the paper.

This work was supported by the National Institute of Neurological Disorders and Stroke-National Institutes of Health (Grants R21NS085508-02 and R01NS083947 to P.B.). We thank Joanne Abrahams for the assistance with images. et al., 2009). These neurobehavioral conditions, including autism, attention deficits, hyperactivity, schizophrenia, and depressive psychosis, are attributed to defects in the development and function of interneurons (Botting et al., 1997; Anderson et al.,

The authors declare no competing financial interests.

Correspondence should be addressed to Praveen Ballabh, Department of Pediatrics and Neuroscience, Albert Einstein College of Medicine-Children's Hospital at Montefiore, Kennedy Center, 1410 Pelham Parkway, Bronx, NY 10461. E-mail:Pballabh@msn.com.

DOI:10.1523/JNEUROSCI.0478-18.2018

Copyright $\odot 2018$ the authors $\quad 0270-6474 / 18 / 387378-14 \$ 15.00 / 0$ 
2004; Indredavik et al., 2010; de Kieviet et al., 2012). Premature birth leads to a loss of intrauterine environment and preterm infants suffer neurological complications, including intraventricular hemorrhage, hypoxic episodes, and sepsis. These factors might disrupt the population of cortical interneurons and other neural cells. Despite all of this, there is a paucity of information on densities of cortical interneuron subtypes during late human pregnancy and the effect of prematurity on interneuron population in the cerebral cortex has not been evaluated. Therefore, we investigated whether preterm birth would affect the heterogeneity of cortical interneurons in the upper (II-IV) and lower (V-VI) cortical layers and, if so, how this can be ameliorated in prematurely born infants.

Our previous studies have shown that the generation of pyramidal neurons continues until 28 gestational week, whereas interneurons are produced until the end of human pregnancy (Malik et al., 2013; Arshad et al., 2016). Continued production of interneurons in late pregnancy renders these cells vulnerable to perinatal brain injury. Pyramidal neurons are derived from ventricular and subventricular zone of dorsal telencephalon, whereas cortical interneurons are born in the medial and caudal ganglionic eminences (MGE and CGE, respectively) (Kepecs and Fishell, 2014). The MGE gives rise to fast-spiking parvalbumin (PV)- and non-fast spiking somatostatin (SST)- expressing interneurons, whereas CGE is the source of bipolar interneurons that express calretinin (CalR) and multipolar interneurons that contain neuropeptide Y (NPY) (Wonders and Anderson, 2006). Approximately $75 \%$ of the CGE-derived interneurons contribute to the upper cortical layers and the remaining 25\% to the lower cortical layers in mice regardless of their birth dates (Rymar and Sadikot, 2007; Miyoshi and Fishell, 2011). During human development, a few $\mathrm{PV}^{+}$perikarya appear in layer $\mathrm{V}$ by 20 weeks and distinct PV immunoreactivity develops in layers II-VI after 26 weeks in an inside-out manner (Cao et al., 1996; Letinic and Kostovic, 1998). SST-expressing neurons are sparse in midterm in human cortex (Zecevic et al., 2011). Even though we have some information on distribution of interneuron subtypes in the cerebral cortex, they have not been systematically quantified in the late human pregnancy because of difficulty in obtaining postmortem tissues from premature infants.

Preterm birth results in termination of in utero environment and cessation of exposure to placental and maternal hormones. Indeed, estrogen level drops 100-fold in newborns upon premature delivery (Trotter et al., 1999). A drop in estrogen level might interrupt both neurogenesis and maturation of interneurons. Accordingly, we have shown that estrogen treatment reverses interneuron neurogenesis in preterm rabbits by cell cycle inhibition and elevation in Ascl1 (Tibrewal et al., 2018). Likewise, a drop in estrogen level in adolescent mice with ovariectomy reduces the density of $\mathrm{PV}^{+}$interneurons in hippocampus, which are restored by estrogen treatment (Wu et al., 2014). Estrogen treatment has also shown to alter transcription of Arx and its downstream targets (Olivetti et al., 2014; Marsh et al., 2016), which is critical for tangential migration and maturation of MGE-derived cortical interneurons (Colasante et al., 2008; Vogt et al., 2014). In addition, estrogen offers neuroprotection by anti-apoptotic and antiinflammatory activity, abrogates white matter injury in animal models of hypoxia-ischemia and hyperoxia, and modulates neuronal plasticity by regulating dendritic spine and synapse formation (Amantea et al., 2005; Gerstner et al., 2007, 2009; Brinton, 2009). Therefore, we hypothesized that interneuronal subtypes, PV, SST, CalR, and NPY, are recruited in the upper and lower cortical layers in a distinct manner. In addition, preterm birth would disrupt the heterogeneity of cortical interneurons, which might be reversed by estrogen treatment. To test these hypotheses, we used autopsy samples from premature infants and, to study the effect of estrogen, we used prematurely delivered embryonic day $28.5(\mathrm{E} 28.5)$ rabbits (term $=32 \mathrm{~d})$.

\section{Materials and Methods}

Human subjects. The Institutional Review Board at New York Medical College and Albert Einstein College of Medicine approved the use of autopsy samples from human fetuses and premature infants for this study. The study materials included brain tissues taken from autopsies of fetuses and premature infants of 20-40 gestational weeks (gw). The autopsy samples were collected at a postmortem interval of $<18 \mathrm{~h}$. Premature infants with moderate to severe intraventricular hemorrhage, major congenital anomalies, history of neurogenetic disorder, chromosomal defects, culture-proven sepsis, meningitis, or hypoxic-ischemic encephalopathy and infants receiving extracorporeal membrane oxygenation treatment were excluded from the study. In addition, any brain tissue showing autolysis or necrosis on hematoxylin and eosin staining was also excluded from the study.

To assess alternation in the density of interneurons in the upper and lower cortical layers as a function of gestational age, we assessed coronal sections from 4 groups of subjects: (1) fetuses of 20-22 gw $(n=5),(2)$ premature infants of 23-28 gw $(n=5),(3)$ late preterm infants of 29-34 gw $(n=5)$, and (4) premature (near-term) infants of 35-40 gw $(n=5)$. Of these, nine were females and 11 were males. This classification enabled equal distribution of subjects in each group. All of these infants died within $5 \mathrm{~d}$ of birth. To determine the effect of prematurity, we compared two groups of infants (Table 1): (1) preterm infants at 27-28 gw (3-4 week postnatal age) versuss $32-33 \mathrm{gw}(<3 \mathrm{~d}$ postnatal age $)$ infants at an equivalent corrected gestational age ( $\sim 33$ weeks) at demise and $(2)$ nearterm infants at $35 \pm 1 \mathrm{gw}$ ( 3 week postnatal age) versus $38 \pm 1 \mathrm{gw}(<3 \mathrm{~d}$ postnatal age) infants at an equivalent corrected gestational age $(\sim 38$ weeks) at the time of death. Five infants were evaluated for each group, so a total of 20 infants were studied to assess the impact of prematurity and prematurity-related complications. These samples were collected during the last 14 years (2002-2016) at Westchester Medical Center of New York Medical College (Valhalla, NY).

Human tissue collection and processing. We processed the brain tissues as described previously (Ballabh et al., 2007). The coronal blocks (4-6 $\mathrm{mm}$ thick) included cortex (cortical plate), white matter (embryonic intermediate layer), and ganglionic eminences, which were cut at the level of the head of caudate nucleus (http://www.brainspan.org/static/ atlas). We fixed the brain slices into $4 \%$ paraformaldehyde in PBS $(0.01$ $\mathrm{M}, \mathrm{pH}$ 7.4) for $18 \mathrm{~h}$ and cryoprotected by immersing into $20 \%$ sucrose in PBS buffer for $\sim 24 \mathrm{~h}$, followed by $30 \%$ sucrose for the next $24 \mathrm{~h}$. The processed slices were frozen after embedding them into optimum cutting temperature compound (Sakura) and stored at $-80^{\circ} \mathrm{C}$ until sectioning. Frozen coronal blocks were then cut into $20-\mu \mathrm{m}$-thick sections using a cryostat and sections were stored at $-80^{\circ} \mathrm{C}$ until use.

Premature rabbits and estrogen treatment. The study was performed with approval from the Institutional Animal Care and Use Committee of New York Medical College. Timed-pregnant New Zealand rabbits were purchased from Charles River Laboratories. We performed C-section to deliver the premature kits at $28.5 \mathrm{~d}$ of gestational age (full-term $=32 \mathrm{~d}$ ). Newborn kits were reared in an infant incubator at a temperature of $35^{\circ} \mathrm{C}$. We used rabbit milk replacer (Zoologic; PetAg) to gavage feed the kits in a volume of $\sim 2 \mathrm{ml}$ every $12 \mathrm{~h}(100 \mathrm{ml} / \mathrm{kg} / \mathrm{d})$ for the first $2 \mathrm{~d}$, and feeds were advanced to $125,150,200,250$, and $280 \mathrm{ml} / \mathrm{kg}$ at postnatal days 3 (P3), P5, P7, P10, and P14, respectively. The rabbit kits were treated with intramuscular $17 \beta$-estradiol (Sigma-Aldrich) in a dose of 200 $\mu \mathrm{g} / \mathrm{kg}$ for $5 \mathrm{~d}$ or until death based on the dosing regimen of previous studies (Picazo et al., 2003; Twining et al., 2013; Corvino et al., 2015). The $17 \beta$-estradiol treatment was initiated within $2 \mathrm{~h}$ of birth (E28.5 kits). Because $17 \beta$-estradiol was dissolved in dimethyl sulfoxide (DMSO), the control kits were treated with intramuscular DMSO for $5 \mathrm{~d}$. Sex determination in the kits was done by performing qRT-PCR on the mRNA isolated from brain tissues. 
Table 1. Characteristics of human fetuses and premature infants

\begin{tabular}{|c|c|c|c|c|}
\hline Gestational age (weeks + days) & Postnatal age (days) & PMA (weeks + days) & Sex & Clinical diagnosis and death \\
\hline \multicolumn{5}{|c|}{ Preterm infants (PMA $=32-33 \mathrm{gw}$ ) } \\
\hline \multicolumn{5}{|c|}{ More premature infants ( $26-27 \mathrm{gw}, 26-49 \mathrm{~d}$ of postnatal age at death) } \\
\hline 26 & 42 & 32 & Male & Clinical sepsis \\
\hline 26 & 43 & $32+1$ & Male & Necrotizing enterocolitis \\
\hline 26 & 49 & 33 & Female & Necrotizing enterocolitis \\
\hline $26+5$ & 35 & $31+5$ & Male & Necrotizing enterocolitis \\
\hline $27+2$ & 26 & 31 & Female & Necrotizing enterocolitis \\
\hline \multicolumn{5}{|c|}{ Less premature infants (32-33 gw, $<4 \mathrm{~d}$ of postnatal age at death) } \\
\hline 33 & 2 & $33+2$ & Male & Nonimmune hydrops \\
\hline $31+6$ & 1 & 32 & Male & Nonimmune hydrops \\
\hline 33 & 1 & 33 & Female & Diaphragmatic hernia \\
\hline $31+5$ & 3 & $32+2$ & Male & lleal perforation, peritonitis \\
\hline 33 & 1 & 33 & Female & Clinical sepsis and shock \\
\hline \multicolumn{5}{|c|}{ Near-term infants (PMA $=37-40 \mathrm{gw})$} \\
\hline \multicolumn{5}{|c|}{ More premature infants (35-37 gw, $14-22$ d of postnatal age at death) } \\
\hline 36 & 8 & $38+3$ & Female & Cardiomyopathy \\
\hline 36 & 22 & $40+1$ & Male & Culture negative sepsis \\
\hline 35 & 14 & 37 & Female & Necrotizing enterocolitis \\
\hline 36 & 14 & 38 & Male & Diaphragmatic hernia \\
\hline 35 & 14 & 37 & Female & Clinical sepsis \\
\hline \multicolumn{5}{|c|}{ Less premature infants ( $37-40 \mathrm{gw}, 1-4 \mathrm{~d}$ of postnatal age at death) } \\
\hline 37 & 2 & $38+2$ & Male & Hypoplastic lung \\
\hline 37 & 1 & $37+1$ & Female & Diaphragmatic hernia \\
\hline 37 & 1 & $37+1$ & Female & Metabolic acidosis, undetermined cause \\
\hline 40 & 1 & $40+1$ & Male & Hypoplastic right heart \\
\hline 38 & 4 & $38+2$ & Male & Diaphragmatic hernia \\
\hline
\end{tabular}

Immunohistochemistry. Immunolabeling was performed as described previously.(Ballabh et al., 2007) The primary antibodies used in experiments included goat polyclonal PV (catalog \#Sc-7449; Sigma-Aldrich), rabbit polyclonal SST (catalog \#mab354, clone YC7; Millipore), mouse monoclonal TLE4 (catalog \#SC-365406; Santa Cruz Biotechnology), rabbit monoclonal NPY (catalog \#22940; ImmunoStar), mouse monoclonal CalR (catalog \#AF5065; R\&D Systems), mouse monoclonal GAD65 (catalog \#ab261130; Thermo Fisher Scientific), rabbit polyclonal Arx (catalog \#PA5-40407; Thermo Fisher Scientific), and mouse monoclonal GAD 67 (catalog \#Mab5406; Millipore). Secondary antibodies used were Alexa Fluor 488-AffiniPure Donkey Anti-Mouse IgG (catalog \#715-545-150), Alexa Fluor 488-AffiniPure Donkey Anti-rabbit IgG (catalog \#711-165-152), Alexa Fluor 594-AffiniPure Donkey Anti-Goat IgG (catalog \#705-585-147), Alexa Fluor 647 Donkey anti-goat (catalog \#A21447) (all from Invitrogen). Briefly, we hydrated the fixed sections in $0.01 \mathrm{M}$ PBS and antigen retrieval was performed by boiling the slides into $0.01 \mathrm{~m}$ sodium citrate, $\mathrm{pH} 6$, for $8-10 \mathrm{~min}$. We then incubated for $2 \mathrm{~h}$ in blocking buffer (5\% donkey or goat serum in PBS with $0.05 \%$ Triton $\mathrm{X}-100)$ at room temperature. We next incubated the sections in primary antibodies diluted in PBS at $4^{\circ} \mathrm{C}$ overnight. After washing in PBS, the sections were incubated with secondary antibody diluted in $1 \%$ normal donkey serum in PBS at room temperature for $\sim 1 \mathrm{~h}$. After washes in PBS, sections were mounted with Slow Fade Light Antifade reagent (Invitrogen) and visualized under a confocal microscope (Nikon Instruments). For each immunolabeling, we used both negative and positive controls. Negative controls were "no primary antibody control," which were made by incubating sections in antibody diluents without primary antibody followed by incubation in secondary antibody. Positive controls were made by staining sections from adult brains, which abundantly express these interneurons.

Quantification of interneurons under confocal microscope. For each brain slice taken at the level of caudate nucleus, three to four coronal sections were studied, which were collected at an interval of $200 \mu \mathrm{m}$ (one section every $200 \mu \mathrm{m}$ ) as described previously (Arshad et al., 2016). The coronal sections were triple labeled with PV-, SST-, and transducin-like enhancer protein 4 (TL4)-specific antibodies. All counting was done on a confocal microscope (EZ-C1 program; Nikon Instruments) using the "point of interest" icon from menu bar. Approximately five or six repre- sentative images from each upper and lower cortical layer were used for quantification. Lower cortical layers were identified by labeling with TLE4 antibody (Hevner, 2007). We quantified PV and SST interneuron subtypes in the upper (II-IV) and lower (V-VI) cortical layers. In addition, another set of coronal sections were labeled with CalR, NPY, and TLE4 antibodies and $\mathrm{CalR}^{+}$and $\mathrm{NPY}^{+}$interneurons were quantified in upper and lower cortical layers. The density of $\mathrm{PV}^{+}$and CalR ${ }^{+}$cells was estimated by $60 \times$ oil-immersion objective (numerical aperture $=1.40$ ) and the SST- and NPY-reactive interneurons were quantified by $20 \times$ oil-immersion lens. All counting was done by two investigators blinded to the groups of the subjects.

To assess the effect of gestational age on interneuron population, all quantifications were done in the upper and lower cortical layers of 4 groups of human subjects, including 20-22, 23-28, 29-34, and 35-40 gw ( $n=5$ each group, 20 subjects total; Table 1$)$. We evaluated approximately five images in the upper and five images in lower cortical layers of each brain section and included three to four sections per brain in the study. Therefore, we counted objects in approximately five images per brain region (upper and lower cortical layer) of each brain section (approximately five images $x$ two brain regions $x$ three to four sections $\times$ 20 brains). To assess the effect of prematurity, we compared the interneuron subtypes between more and less premature infants in two subsets of infants: preterm and near-term. Within preterm groups, 26-27 gw infants (more premature) were compared with $33 \mathrm{gw}$ infants (less premature) at equivalent postmenstrual age (PMA). Similarly, within the near-term group, 34-36 gw infants were compared with 37-40 gw infants, an equivalent PMA. Stereological protocol was not followed for the quantification of cells in human brains because of the limitations of our system in identification of far-red signals from triple-labeled sections. Cell diameters were measured with a confocal microscope (EZ-C1; Nikon) using the "scale bar" tool from menu. We drew a line across the largest diameter of a cell using the scale bar tool and this reflected the diameter of a neuron.

Stereological quantification of interneurons using optical dissector method in rabbits. Unbiased stereology methods, with assistance from a computerized software system (Stereologer; Stereology Resource Center) were used to quantify $\mathrm{PV}^{+}$and SST ${ }^{+}$interneurons in the upper and 
lower cortical layers in double-labeled sections using PV or SST with TLE-specific antibodies. Dual color filter set (filter set 74 HE GFP_mRFP shift free; Zeiss) in the fluorescent microscope was used to assess both PV/SST (red) and TLE (green) at the same time. Briefly, coronal sections were cut on cryostat at a setting of $30 \mu \mathrm{m}$ thickness with a section sampling interval of three $(90 \mu \mathrm{m})$ to achieve at least five sections at the level of midseptal nucleus. The quantification was performed as follows. The reference spaces (upper and lower cortical layer) were first outlined on the section under a $5 \times$ objective. $\mathrm{TLE}^{+}$neurons indicated the lower cortical layer. The volume of the outlined area (reference space) was quantified using a point-counting probe (frame, $25 \times 25 \mu \mathrm{m}$; guard zone, $2 \mu \mathrm{m}$; interframe interval, $300 \mu \mathrm{m}$ ). Interneuron count for each subtype was performed using the optical dissector method (frame, $25 \times$ $25 \mu \mathrm{m}$; guard zone, $2 \mu \mathrm{m}$; interframe interval, $280 \mu \mathrm{m}$ ) under $20 \times$ objective, keeping the coefficient of error at $<0.1$. We quantified Arx and Dlx2 double-labeled cells in the ventral subventricular zone (SVZ) in a similar manner (frame, $20 \times 20 \mu \mathrm{m}$; guard zone, $2 \mu \mathrm{m}$; interframe interval, $350 \mu \mathrm{m})$.

Western blot analyses. We homogenized the frozen brain tissue in a sample buffer (3\% SDS, 10\% glycerol, $62.5 \mathrm{~mm}$ Tris- $\mathrm{HCl}$ ) using a mechanical homogenizer. The protein concentration in the supernatant was estimated using a BCA Protein Assay Kit (catalog \#23227; Pierce). Total protein samples were separated by SDS-PAGE according to a previously described protocol.(Ballabh et al., 2007) Equal amounts of protein (25 $\mu \mathrm{g})$ were diluted in Laemmli buffer (Bio-Rad) and boiled for $5 \mathrm{~min}$ before being loaded onto a $4-15 \%$ gradient precast gel (Bio-Rad). The separated proteins were transferred onto PVDF membrane by electrotransfer. The membranes were next incubated with primary antibodies, including mouse monoclonal Dlx1 (catalog \#75-078; Neuromab), rabbit polyclonal Sox6 (catalog \#HPA001923-100UL; Sigma-Aldrich), mouse monoclonal Cxcr4 (catalog \#SC-53534; Santa Cruz Biotechnology), mouse monoclonal GAD65 (catalog \#ab261130; Santa Cruz Biotechnology), mouse monoclonal Lmo3 (catalog \#SC-17019; Santa Cruz Biotechnology), rabbit polyclonal Arx (catalog \#PA5-40407; Thermo Fisher Scientific), and mouse monoclonal GAD67 (catalog \#Mab5406; Millipore). Target proteins were detected with chemiluminescence ECL system (GE Healthcare) using secondary antibodies conjugated with horseradish peroxidase (Jackson ImmunoResearch Laboratories). We next stripped the blots with stripping buffer (Pierce) and incubated with $\beta$-actin mouse monoclonal primary antibody (Sigma-Aldrich) followed by secondary antibody and detection with a chemiluminescence ECL system. As described previously (Ballabh et al., 2007), the blots from each experiment were densitometrically analyzed using ImageJ. The optical density was normalized by taking the ratio of the target protein and $\beta$-actin.

$q R T-P C R$. Gene expression was assayed by real-time qRT-PCR as described previously (Ballabh et al., 2007; Vinukonda et al., 2016). Briefly, total RNA was isolated using a RNeasy Mini kit (catalog \#74104; Qiagen) from a coronal brain slice taken at the level of the midseptal nucleus. cDNA was synthesized using Superscript II RT enzyme (catalog \#05081955001; Roche) followed by a real-time quantitation using an ABI Prism 7900HT detection system. TaqMan probes were from Life Technologies. Their assay IDs were as follows: GAPDH (Oc03823402_g1), Ascl1 (AJD1UIG), Lhx6 (AIT975S), GAD1 (Hs01065893-m1), GAD2 (Hs00609534_m1), ARX (ARRWE4X), Shox2 (ARZTEKG), LHX6 (AJLJJR), and rabbit SRY (NM_001171148.1).

Statistics and analysis. Data are shown as mean \pm 1 SEM. To determine the impact of gestational age, including 20-22, 23-28, 29-34, and 35-40 gw, on the density of interneuron subtypes, one-way ANOVA was used for upper and lower cortical layers separately. To compare between gestational groups within upper or lower layer, we performed post hoc Tukey's test. The differences in the density of interneuron subtypes between upper and lower cortical layers were calculated using unpaired $t$ test. Two group comparisons for more premature versus less premature infants and estrogen versus vehicle treatment were also performed using unpaired $t$ test. $p<0.05$ was considered significant.

\section{Results}

Number of $\mathrm{PV}^{+}$cells in the cortex increases with gestational age in both upper and lower cortical layers

$\mathrm{PV}$-immunoreactive interneurons have been studied in fetal human brain until mid-pregnancy, but not well characterized in the third trimester (Cao et al., 1996; Rakic and Zecevic, 2003; Jakovcevski et al., 2011). Therefore, we evaluated $\mathrm{PV}^{+}$interneurons in upper (II-IV) and lower (V-VI) cortical layers of fetuses and preterm infants of 20-40 gw. Few cortical $\mathrm{PV}^{+}$cells were observed in infants of 28 gw or less, whereas they were twice more numerous in infants of 28 gw or more. These cells were unipolar, bipolar, or sometimes multipolar in morphology, with immunoreactivity evident in both somata and neuropils. Accordingly, the cell body was triangular, ovoid, or circular (Fig. 1). The staining of the cell bodies was weak in the center and relatively intense near the cell margin in subjects of $<28 \mathrm{gw}$, which is consistent with previous studies in the visual cortex of preterm infants (Cao et al., 1996). In $>28$ gw infants, the immunoreactivity was stronger in both the center and periphery of the somata. The cells were radially arranged with processes facing toward pia mater. The size of cell body was $12.65 \pm 0.366 \times 8.7 \pm 0.37 \mu \mathrm{m}^{2}$ (maximal and minimal diameter) in the cortex of near-term and term infants (35-40 gw).

We quantified $\mathrm{PV}^{+}$cells in the upper and lower cortical layers of four subsets of subjects: $20-22,23-28,29-34$, and 35-40 gw (Fig. 1A). Immunolabeling of coronal sections with PV- and TLE4 (a lower cortical layer marker)-specific antibodies showed that the density of $\mathrm{PV}^{+}$neurons increased with advancing gestational age in both upper and lower cortical layers $(p<0.001$ both, one-way ANOVA). Accordingly, within the upper cortical layer, the density of $\mathrm{PV}^{+}$interneurons was higher in 29-34 and 35-40 gw infants compared with both 20-22 and 23-28 gw subjects ( $p<0.001$ all, Tukey's post hoc test). However, the comparisons for 36-40 versus 31-34 gw and 23-28 versus 20-22 were not significant in the upper layer ( $p=0.61$ and 0.9 , respectively). Likewise, within the lower cortical layer, the $\mathrm{PV}^{+}$cells were more numerous in 35-40 gw compared with 20-22 and 23-28 gw infants $(p=0.002,0.004$, Tukey's test) and more abundant in $29-34$ gw relative to $20-22$ gw infants $(p=0.04)$. We next compared the density of $\mathrm{PV}^{+}$neurons between the upper and lower cortical layers for four gestational age categories and found that the density of $\mathrm{PV}^{+}$cells was comparable between the two layers ( $p=0.2,0.1,0.14$, and 0.3 , respectively, unpaired $t$ test). The population of $\mathrm{PV}^{+}$interneurons increased as a function of gestational age and was similar between the upper and lower cortical layers.

\section{Number of $\mathrm{SST}^{+}$cells increases with gestational age in lower cortical layers}

We evaluated SST ${ }^{+}$interneurons in the upper and lower cortical layers for 20-40 gw fetuses and premature infants in coronal sections stained with SST- and TLE4-specific antibodies (Fig. 1B). We found that $\mathrm{SST}^{+}$interneurons were few relative to $\mathrm{PV}^{+}$ cells. They were commonly bipolar or multipolar in morphology and their cell bodies were relatively larger compared with $\mathrm{PV}^{+}$ interneurons $\left(17.8 \pm 1.09 \times 7.4 \pm 0.36 \mu \mathrm{m}^{2}\right)$. Their immunoreactivity was uniformly intense in the somata and neuropils.

We next assessed the density of $\mathrm{SST}^{+}$cells in the upper and lower cortical layers (Fig. 1). We found that the density of SST ${ }^{+}$ interneurons remained consistent across gestational age $(20-40$ $\mathrm{gw}$ ) in the upper cortical layer ( $p=0.7$, one-way ANOVA). However, $\mathrm{SST}^{+}$cells increased in lower layers with advance in gestational age ( $p=0.011$, one-way ANOVA). Comparisons between 


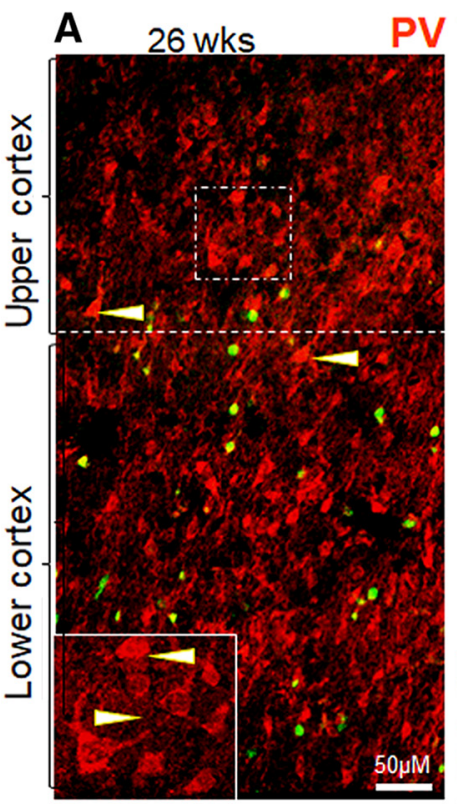

A'

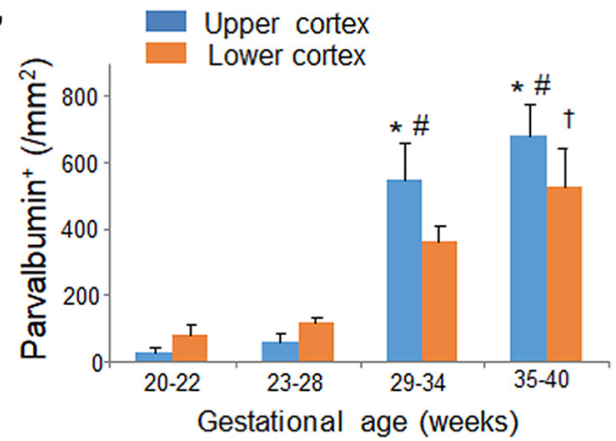

B
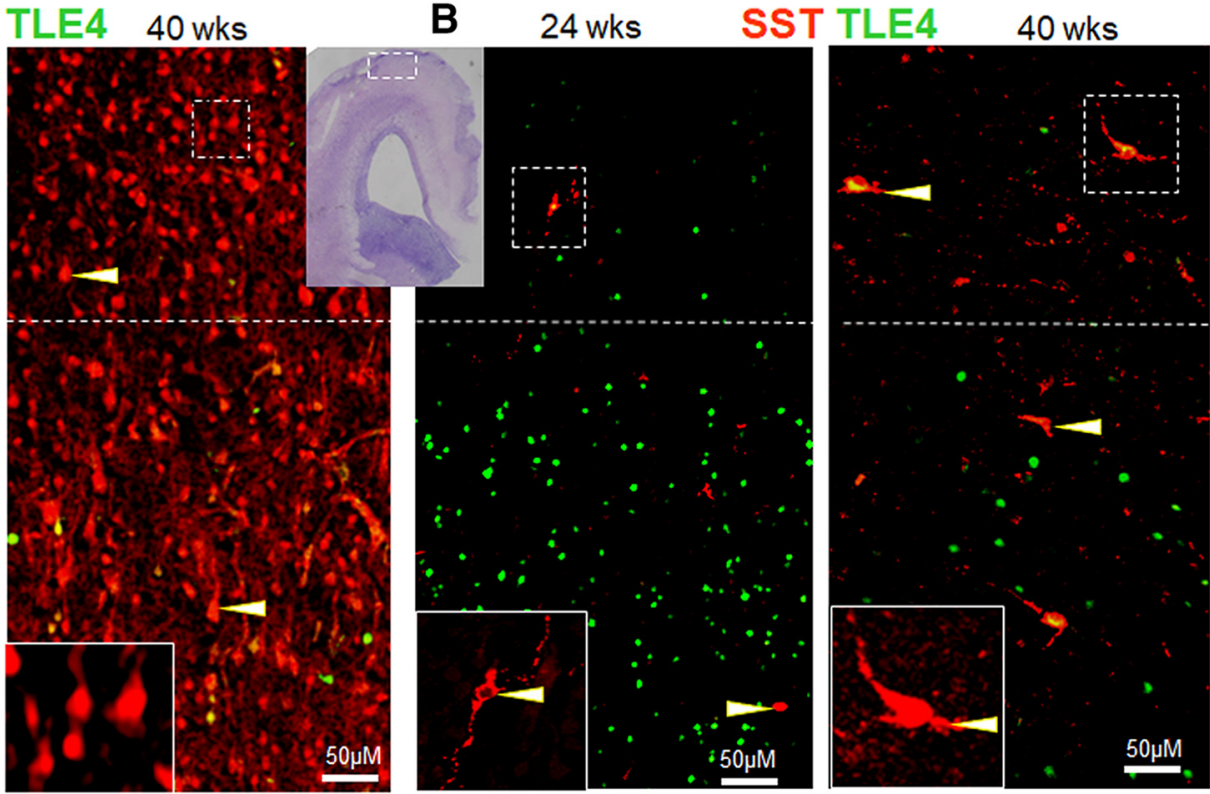

Upper cortex

B'

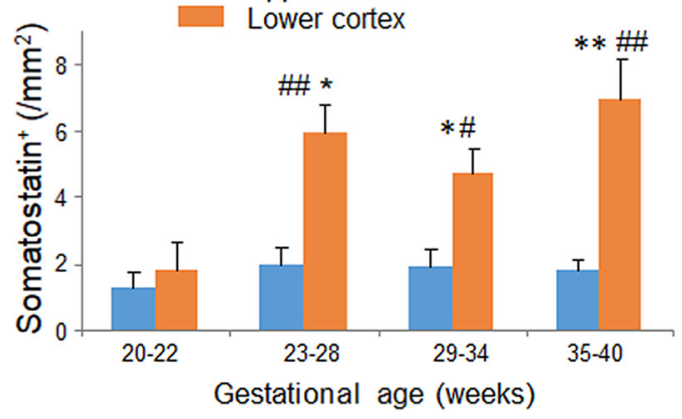

Figure 1. PV increases as a function of gestational age, but not SST. A, Representative immunofluorescence of cryosections from upper and lower cortical layers of 26 and 40 -week infant (as indicated) labeled with PV and TLE4 antibodies. Insets are high-magnification view of the boxed area in the image. The lower cortical layer shows expression of TLE4 ${ }^{+}$(green) cells, which is relatively absent in the upper cortical layer. The dashed line denotes the separation of lower and upper cortical layer. PV ${ }^{+}$cells are more densely packed in $40 \mathrm{gw}$ compared with $26 \mathrm{gw}$ infant. Immunoreactivity of PV ${ }^{+}$cells was weak and predominantly near the cell margin in $26 \mathrm{gw}$ infant (arrowhead), whereas staining was equally intense in both center and periphery of the cell in $40 \mathrm{gw}$ infant (arrowhead). Cresyl violet-stained section in the top center has a boxed area in the cortex, where the cells were quantified in upper and lower cortical layers. Scale bar, $50 \mu \mathrm{m} . \boldsymbol{B}$, Cryosections from upper and lower cortical layers of $24 \mathrm{gw}$ and $40 \mathrm{gw}$ infant (as indicated) labeled with SST and TLE4 antibodies. Note abundance of TLE4 ${ }^{+}$(green) cells in the lower cortical layer. SST ${ }^{+}$cells were scarce compared with PV ${ }^{+}$cells. SST ${ }^{+}$cells (arrowhead) were fewer in $24 \mathrm{gw}$ compared with $40 \mathrm{gw}$ infant. Scale bar, $50 \mu \mathrm{m} ; \boldsymbol{A}^{\prime}$ ) Data are mean \pm SEM ( $n=5$ each group). The density of PV ${ }^{+}$ cells increased with advancing gestational age in both upper and lower cortical layers. ${ }^{*} p<0.001,20-22 \mathrm{gw}$ vs $29-34$ and $35-40 \mathrm{gw}$ infants in upper cortical layer; $\# p<0.001,23-28 \mathrm{gw}$ vs $29-34$ and $35-40 \mathrm{gw}$ infants in upper cortical layer; $\nmid p<0.01,20-22 \mathrm{gw}$ vs $29-34$ and $35-40 \mathrm{gw}$ in lower cortical layer $\boldsymbol{B}^{\prime}$ ). Data are shown as mean \pm SEM ( $n=5$ each group). The density of SST ${ }^{+}$cells did not change with an increase in the gestational age in the upper cortical layer. In the lower cortical layer, densities of SST ${ }^{+}$cells were higher in $23-28,29-34$, and 35-40 gw compared with $20-22 \mathrm{gw}$ subjects. SST ${ }^{+}$cells were higher in density in lower relative to upper cortical layer, as indicated. ${ }^{*} p<0.05,{ }^{* *} p<0.01$ for the comparison between upper and lower cortical layer within a gestational age category; $\# p<0.05$ or \#\#p $<0.01$ for the comparison of $20-22$ week vs $23-28,29-34$, or $35-40$ gw infants in the lower cortical layer. Upper cortex, Upper cortical layer; lower cortex, lower cortical layer.

gestational age categories showed that the densities of $\mathrm{SST}^{+}$cells were higher in 23-28, 29-34, and 35-40 gw infants compared with $20-22 \mathrm{gw}$ fetuses in the lower layer $(p=0.04,0.038$ and 0.009 , respectively; Tukey's test; Fig. $\left.1 B^{\prime}\right)$. We next compared the density of SST ${ }^{+}$cells between the upper and lower cortical layers and found that they were more abundant in lower layers relative to the upper cortical layers for 23-28, 29-34, and 35-40 gw ( $p<$ $0.006,0.03$, and 0.007 , respectively, unpaired $t$ test), but not for $20-22$ gw $\left(p=0.5\right.$; Fig. $\left.1 B^{\prime}\right)$.

Collectively, there was a surge in the density of $\mathrm{SST}^{+}$cells in the lower cortical layer at 23-28 gw, whereas the SST population in the upper cortical layers remained largely unchanged across 20-40 gw. Data suggest that $\mathrm{SST}^{+}$interneurons in lower cortical layer are rapidly recruited within a narrow window near to the end of second trimester of pregnancy. A lack of increase in $\mathrm{SST}^{+}$ interneurons in upper cortical layer suggests that these interneu- rons are uniformly recruited between 20 and 40 gw, which keeps their density relatively unchanged despite increasing brain volume with advancing gestational age.

\section{Reduced $\mathrm{PV}^{+}$and excess $\mathrm{SST}^{+}$neurons in cerebral cortex of premature infants}

Premature birth is associated with neurobehavioral disorders (Trotter et al., 1999; Anderson et al., 2003), which might be attributed to disrupted production and maturation of interneurons due to a loss of intrauterine environment in these infants. Therefore, we chose to assess the effect of prematurity on the density of cortical interneurons. To this end, we compared the density of $\mathrm{PV}^{+}$and $\mathrm{SST}^{+}$neurons between less premature (higher gestational age) and more premature (lower gestational age) infants, who were of equivalent PMA (gestational age + postnatal age) at the time of death. We evaluated two sets of 

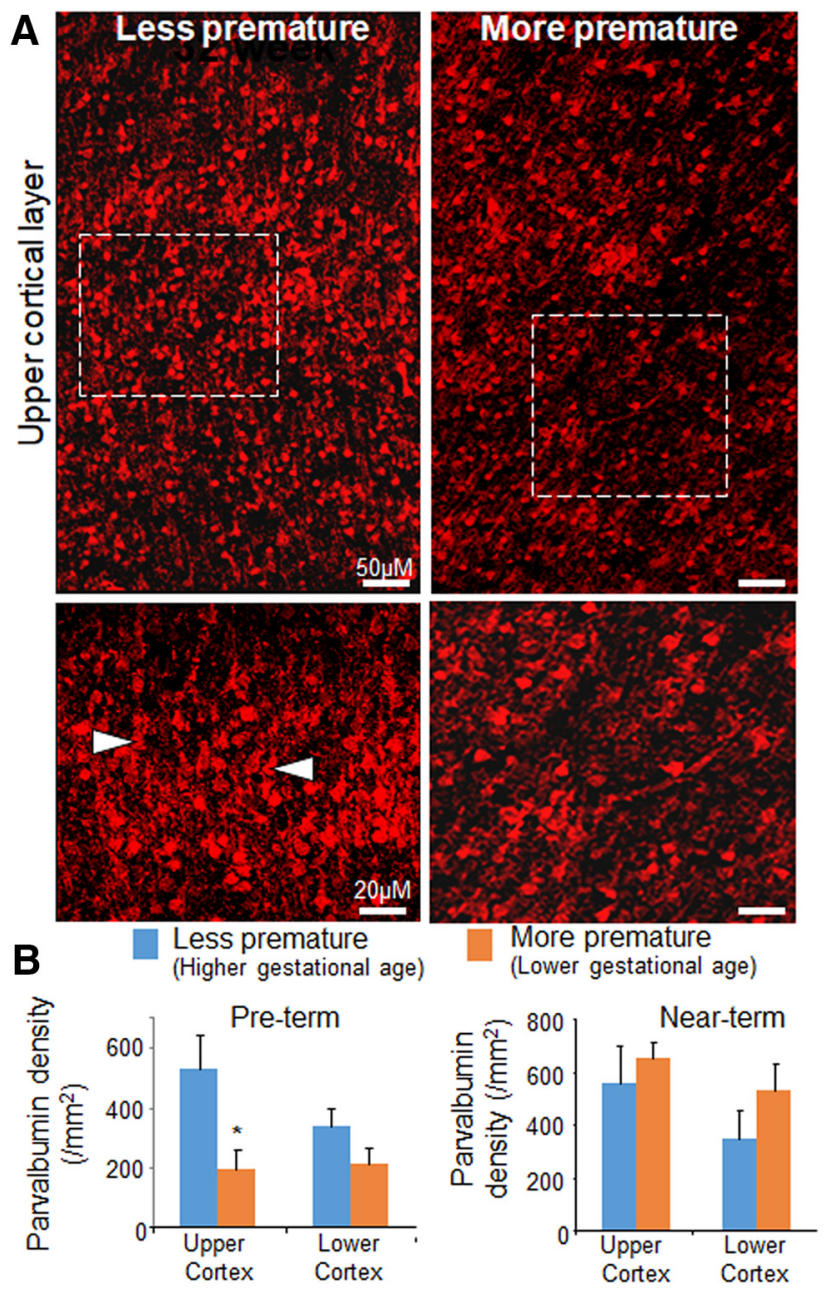
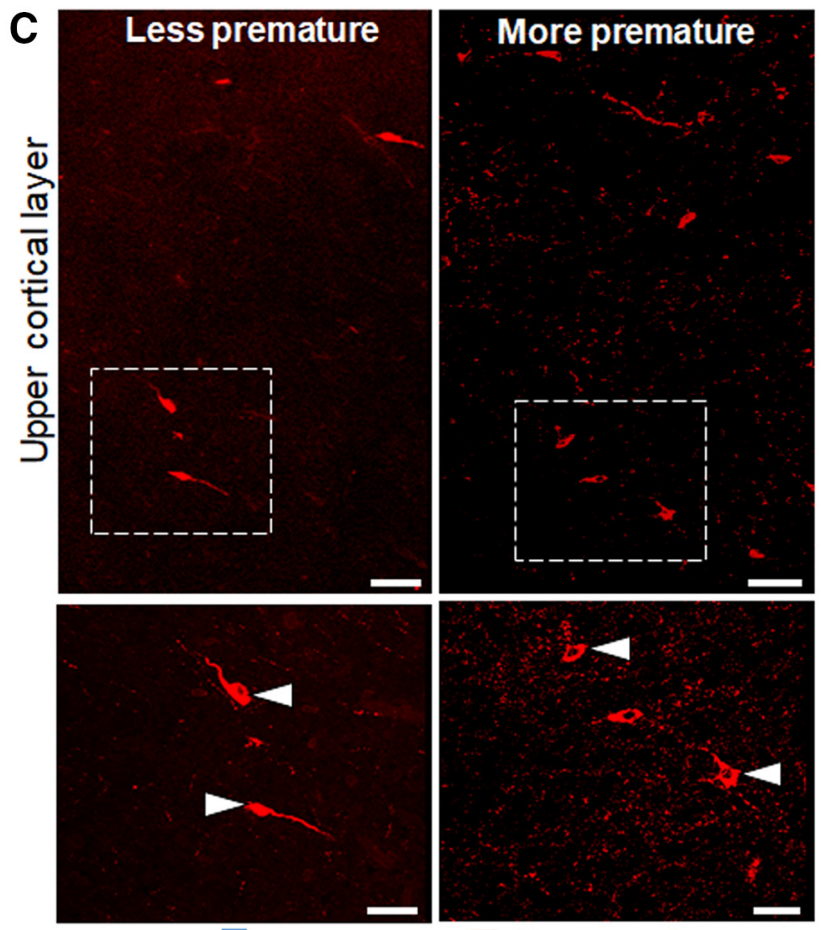

D

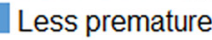

More premature

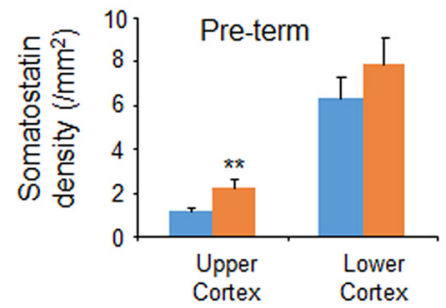

Figure 2. Premature birth induces PV deficit and excess of SST. A, Representative immunofluorescence of cryosections from upper cortical layer of more premature ( $28 \mathrm{gw}+26 \mathrm{~d}$ postnatal age) and less premature ( $32 \mathrm{gw}+3 \mathrm{~d}$ postnatal age) infants labeled with PV-specific antibody. Bottom images are high-magnification view of the boxed area in the top panel. Note increased density of $\mathrm{PV}^{+}$interneurons (arrowhead) in less premature infant relative to more premature infant. Scale bar, $50 \mu \mathrm{m}$ for the top image and $20 \mu \mathrm{m}$ for the bottom image. $\boldsymbol{B}$, Data are mean $\pm \mathrm{SEM}(n=$ 5 each group). Among preterm infants, $\mathrm{PV}^{+}$cells were fewer in more premature infant ( $27-28 \mathrm{gw}$ ) compared with less premature infants (32-33 gw) in the upper cortical layer. However, in near-term infants, $\mathrm{PV}^{+}$cells were similar between 34 and $36 \mathrm{gw}$ (more premature) and $37-39 \mathrm{gw}$ (less premature) in both the upper and lower cortical layers. ${ }^{*} p<0.05$ for more premature versus less premature infants. C, Cryosections from more premature ( $28 \mathrm{gw}+26 \mathrm{~d}$ postnatal age) and less premature ( $32 \mathrm{gw}+3 \mathrm{~d}$ postnatal age) infants were labeled with SST-specific antibody. Note that $\mathrm{SST}^{+}$neurons (arrowhead) were higher in density in more premature infants relative to less premature ones. Scale bar, $50 \mu \mathrm{m}$ for the top image and $20 \mu \mathrm{m}$ for the bottom image. $\boldsymbol{D}$, Data are shown as mean \pm SEM ( $n=5$ each group). For preterm infants, $\mathrm{SST}^{+}$cells were higher in number in more premature ( $\left.27-28 \mathrm{gw}\right)$ compared with less premature infants ( $\left.32-33 \mathrm{gw}\right)$ in the upper cortical layer. However, among near-term infants, $\mathrm{SST}^{+}$cells were comparable between more premature ( $34-36 \mathrm{gw}$ ) and less premature ( $\left.37-39 \mathrm{gw}\right)$ infants in the both the upper and lower cortical layers. ${ }^{* *} p<0.01$ for more premature versus less premature infants.

infants: preterm and near term. Within the preterm group, 26-27 gw infants surviving for 4-6 weeks were compared with 32-33 gw infants who lived for $\leq 3 \mathrm{~d}$. Therefore, the infants in two groups under comparison had a PMA of $\sim 33$ gw at their death. Likewise, within the near-term group, 34-36 gw (3 week postnatal age) infants were compared with $37-40 \mathrm{gw}$ ( $<3 \mathrm{~d}$ postnatal age) infants at a PMA of $\sim 39 \mathrm{gw}$.

We found that 26-27 gw (more premature) infants have fewer $\mathrm{PV}^{+}$neurons compared with 32-33 gw (less premature) infants in the upper cortical layer ( $p=0.02$, unpaired $t$ test), but not in the lower cortical layer ( $p=0.07$; Fig. $2 A, B)$. We next compared $34-36$ and 37-40 gw near-term infants and found no difference in the density of $\mathrm{PV}^{+}$neurons between the two groups of infants in upper or lower cortical layers $(p=0.47$ and $p=0.74$, respectively; Fig. 2B).

We next quantified SST ${ }^{+}$interneurons in the above subsets of infants. The density of SST ${ }^{+}$cells in the upper cortical layers was elevated in $26-27 \mathrm{gw}$ compared with $32-33$ gw infants $(p=$
0.006, unpaired $t$ test; Fig. $2 C, D)$. However, they were similar in number in the lower cortical layers $(p=0.07)$. The comparison within subsets of near term infants did not show any difference in the population of SST ${ }^{+}$interneurons in upper or lower cortical layers $(p=0.8$ and 0.9 ; Fig. $2 D$ ). Together, our data showed that preterm birth is associated with a deficit of $\mathrm{PV}^{+}$interneurons and an abundance of SST ${ }^{+}$interneurons for preterm infants (33 gw PMA), but not for near-tem infants (39 gw PMA).

\section{CalR is enriched in upper cortical layer and NPY is enriched}

in lower cortical layer and there was no effect of preterm birth on their populations

$\mathrm{CalR}^{+}$and $\mathrm{NPY}^{+}$interneurons have been studied in fetal human brain until midpregnancy (Jakovcevski et al., 2011; Radonjić et al., 2014); however, they have not been well characterized during late gestation. Therefore, we evaluated $\mathrm{CalR}^{+}$and $\mathrm{NPY}^{+}$interneurons in coronal sections labeled with TLE4-, NPY-, and CalR-specific antibodies (Fig. $3 A$ ). $\mathrm{CalR}^{+}$cells were bipolar or 
A
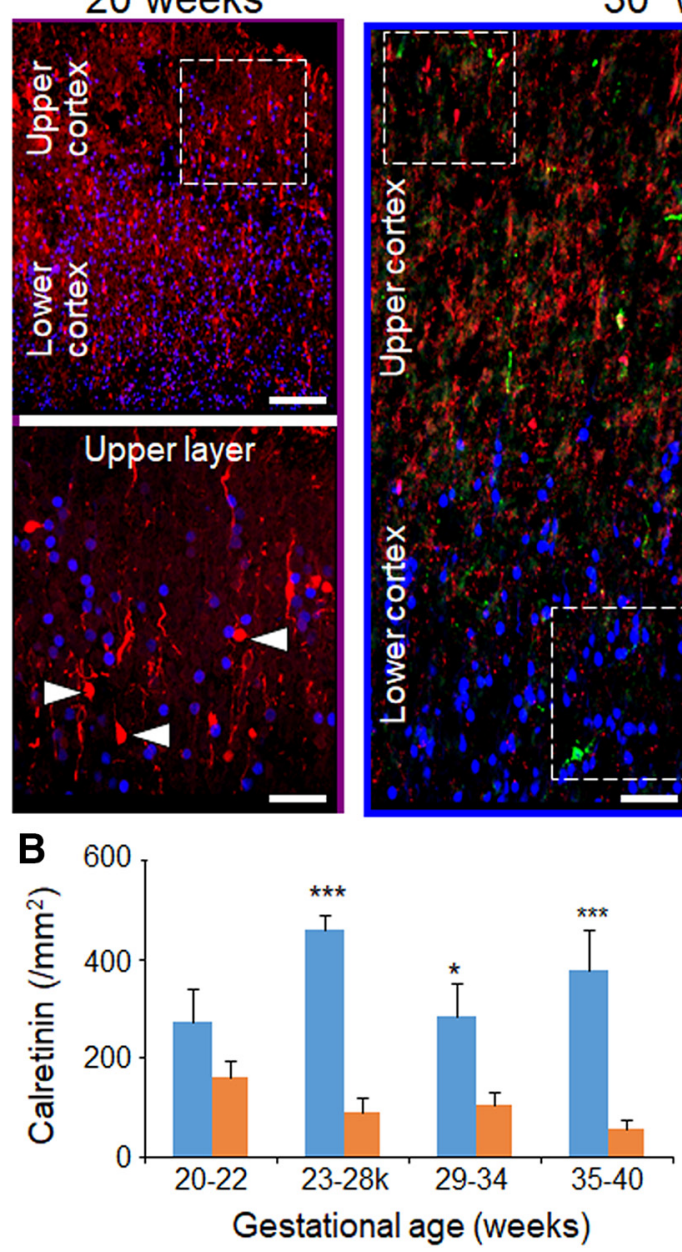

CaIR NPY TLE4

30 weeks
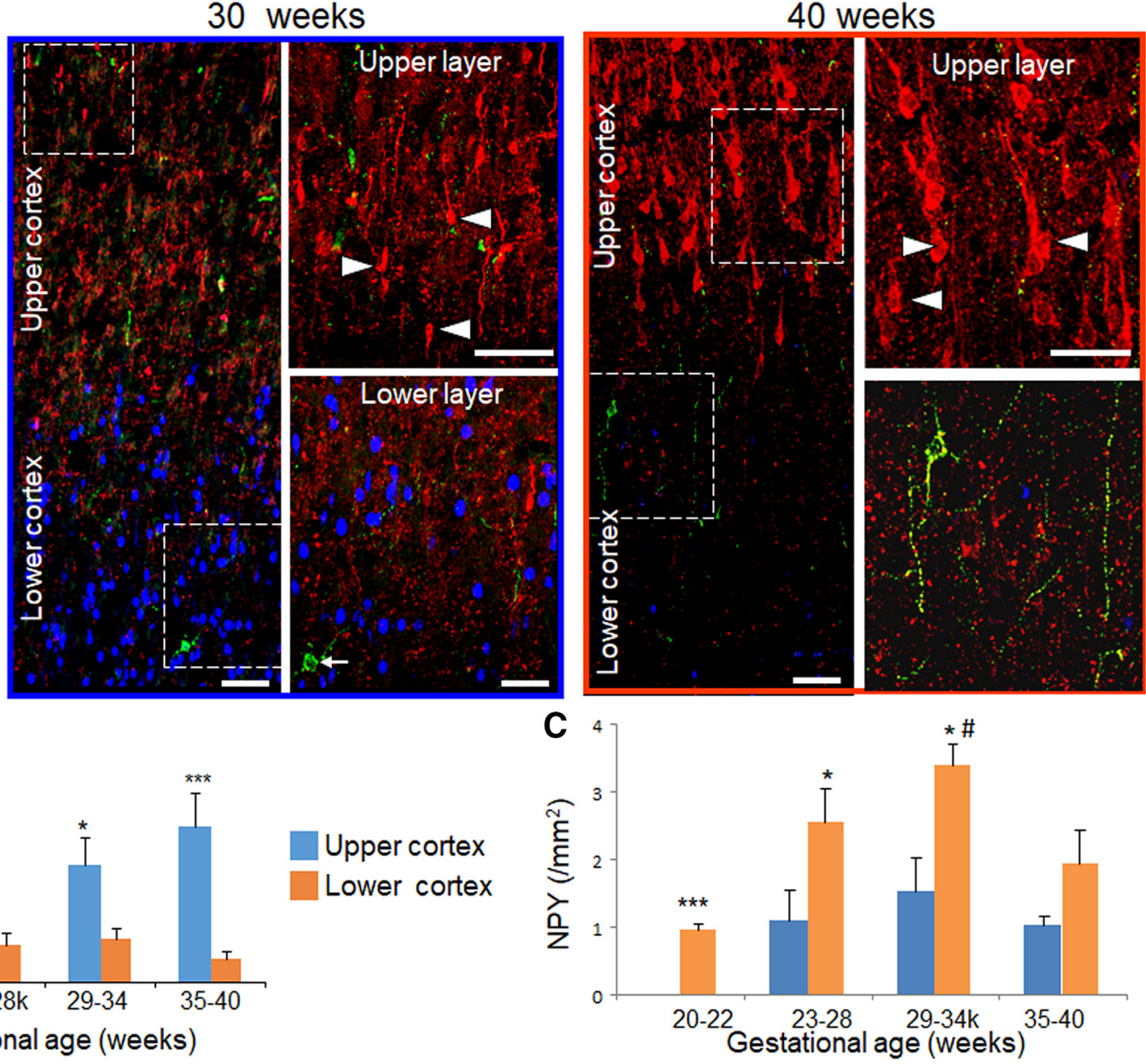

Figure 3. CalR is enriched in upper cortical layer and NPY is enriched in the lower cortical layer. $\boldsymbol{A}$, Representative immunofluorescence of cryosections from upper and lower cortical layers of 20 , 30, and $40 \mathrm{gw}$ infant (as indicated) labeled with CalR-, NPY-, and TLE4-specific antibodies. For the $20 \mathrm{gw}$ image, bottom shows high-magnification of the boxed area at the top. For the 30 and 40 gw infant, images on the right are high-power views of the boxed areas on the left. Note higher density of CalR in the upper cortical layer compared with lower cortical layer. Note relatively fewer number of NPY ${ }^{+}$cells compared with the density of CaIR. Scale bar, $50 \mu \mathrm{m}$ for the left and $20 \mu \mathrm{m}$ for the right panel for each image. $\boldsymbol{B}$, Data are shown as mean \pm SEM ( $n=5$ each group). The density of CalR ${ }^{+}$cells was consistently higher in upper compared with lower cortical layer for $23-28,29-34$, and 35-40 gw infants. ${ }^{*} p<0.05$ and ${ }^{* * *} p<0.001$ for comparison between upper versus lower cortical layer within a gestational age category. C, Data are shown as mean \pm SEM ( $n=5$ each group). NPY ${ }^{+}$interneurons in the lower cortical layer were higher in density in $29-34$ gw compared with $20-22$ gw infants. NPY ${ }^{+}$interneurons were more abundant in lower compared with upper cortical layer as indicated. ${ }^{*} p<0.01,{ }^{* * *} p<0.001$ for the comparison between upper and lower cortical layer within a gestational age category; $\# p<0.05$ for the comparison between 20 and 22 and $29-34$ gw within lower cortical layer.

bitufted in morphology and the shape of perikaryon was fusiform or oval. They were vertically oriented and their dendrites were directed toward layer 1 . They were clearly more abundant in the upper cortical layer relative to the lower cortical layer. NPY ${ }^{+}$ interneurons were fewer relative to $\mathrm{CalR}^{+}$interneurons and they were bipolar, bitufted, or multipolar in shape.

We quantified CalR ${ }^{+}$interneurons in the upper and lower cortical layers across all gestational age categories. The density of $\mathrm{CalR}^{+}$cells did not significantly change in the upper or lower cortical layer as a function of gestational age $(p=0.18$ and $p=$ 0.11 , respectively, one-way ANOVA). However, the number of $\mathrm{CalR}^{+}$cells was higher in the upper compared with lower cortical layer for 23-28, 29-34, and 35-40 gw infants $(p=0.001, p=$ 0.04 , and $p=0.001$, respectively, unpaired $t$ test; Fig. $3 B$ ), but not for 20-22 gw $(p=0.17)$.

We next quantified $\mathrm{NPY}^{+}$interneurons in the upper and lower cortical layers. The density of $\mathrm{NPY}^{+}$interneurons was $\sim 20$ times less relative to $\mathrm{CalR}^{+}$interneurons in both the upper and lower cortical layers. We observed a surge in the density of $\mathrm{NPY}^{+}$ interneurons around 23 gw in lower layers. Accordingly, NPY ${ }^{+}$ interneuron population increased as a function of gestational age in the lower layer $(p<0.016$, one-way ANOVA), but not in the upper layer $(p=0.051)$. Further analysis showed that $\mathrm{NPY}^{+}$ interneurons were higher in density in 29-34 gw compared with $20-22$ gw infants in the lower cortical layer ( $p=0.025$, Tukey's post hoc test; Fig. $3 C$ ). Importantly, the number of $\mathrm{NPY}^{+}$subtypes was greater in the lower cortical layer relative to the upper cortical layer for 20-22, 23-28, and 29-34 gw subjects ( $p=$ $0.001, p=0.02$, and $p=0.03$, respectively, unpaired $t$ test), but not for 35-40 gw infants $(p=0.13)$.

We next assessed the effect of prematurity on $\mathrm{CalR}^{+}$and $\mathrm{NPY}^{+}$cells in preterm (33 gw PMA) and near-term (39 gw PMA) infants. There was no difference in the density of CalR ${ }^{+}$interneurons between more premature and less premature neonates in the preterm (27-28 vs 32-33 gw: $p=0.7$ and $p=0.8$ for upper and lower layer, respectively, unpaired $t$ test) and near-term (34-36 vs $37-40 \mathrm{gw} ; p=0.4$ and $p=0.8$ for upper and lower layer, respectively) groups of infants. Likewise, there was no difference 
A
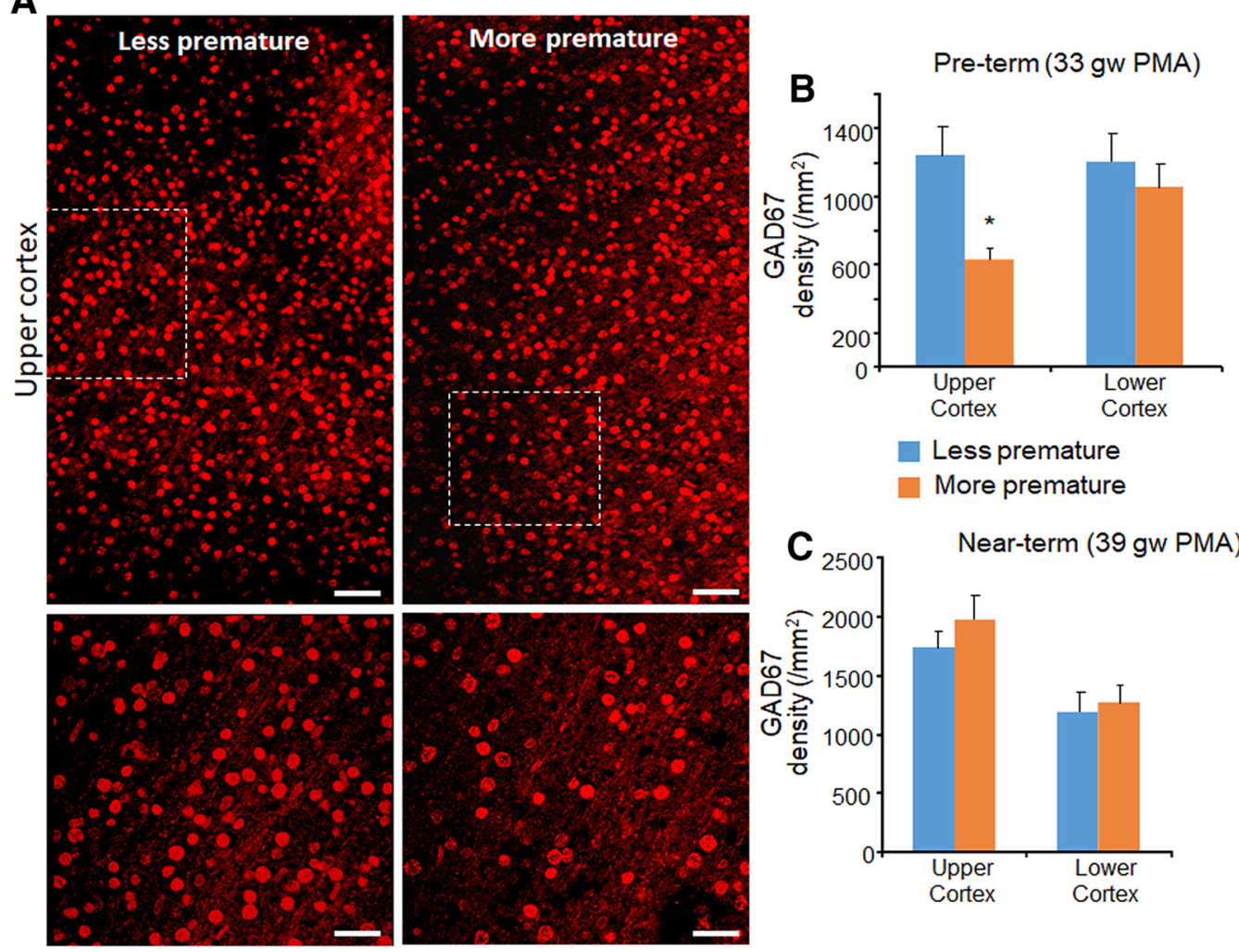

Figure 4. Preterm birth reduced the population of $\mathrm{GAD} 67^{+}$cells. $A$, Representative immunofluorescence of cryosections from more premature ( $28 \mathrm{gw}+26 \mathrm{~d}$ postnatal age) and less premature (32 gw $+3 \mathrm{~d}$ postnatal age) infant labeled with GAD67-specific antibody. Bottom images are high-magnification views of the boxed areas at the top. Note higher number of GAD67 ${ }^{+}$interneurons in less premature infant compared with more premature infant. Scale bar, $50 \mu \mathrm{m}$ for the top image and $20 \mu \mathrm{m}$ for the bottom image. $\boldsymbol{B}$, Data are shown as mean \pm SEM ( $n=5$ each group). Among preterm infants, $\mathrm{GAD}^{+}{ }^{+}$cells were reduced in number in more premature infants (27-28 gw) compared with less premature infants (32-33 gw) in the upper cortical layer. C, Data are shown as mean \pm SEM ( $n=5$ each group). Among near-term infants, $\mathrm{GAD} 7^{+}$cells were comparable between infants of more premature ( $34-36 \mathrm{gw}$ ) and less premature infant ( $37-39 \mathrm{gw}$ ) in both upper and lower cortical layers. ${ }^{*} p<0.05$ for more premature versus less premature infants.

in the density of $\mathrm{NPY}^{+}$neurons between more premature and less premature neonates in the preterm $(p=0.7$ and $p=0.8$ for upper and lower layer, respectively) and near-term ( $p=0.4$ and $p=0.8$ for upper and lower layer, respectively) groups of infants.

Our results show that $\mathrm{CalR}^{+}$interneurons outnumber $\mathrm{NPY}^{+}$ neurons in the cerebral cortex, $\mathrm{CalR}^{+}$interneurons are more abundant in the upper cortical layer and $\mathrm{NPY}^{+}$in the lower cortical layer, and premature birth does not affect the density of $\mathrm{CalR}^{+}$and $\mathrm{NPY}^{+}$interneurons.

\section{Preterm birth reduces GAD67 population in humans}

GAD67 labels GABAergic interneurons and $\mathrm{PV}^{+}$cells constitute approximately half of their population (Marín, 2012). More importantly, the present study showed that preterm birth reduced the population of $\mathrm{PV}^{+}$interneurons in the upper cortical layer. Therefore, we reasoned that preterm birth might reduce the density of GAD $67^{+}$cells. To investigate this, we evaluated GAD67 ${ }^{+}$ cells as a function of gestational age and assessed the effect of preterm birth on this subset of interneurons. GAD67 immunoreactivity was weak and a satisfactory immunolabeling could not be accomplished for preterm infants of $30 \mathrm{gw}$ or less. Therefore, to determine the density of GAD67 ${ }^{+}$cells as function of gestational age, we evaluated brains from two groups of infants, 30-34 and 35-40 gw, who died at $<4$ postnatal days. We found that the density of GAD $67^{+}$cells was comparable between 30 and 34 and $35-40 \mathrm{gw}$ infants for upper or lower cortical layers ( $p=0.51$ and 0.33 , respectively). In addition, there was no significant differ- ence in the population of $\mathrm{GAD} 67^{+}$interneurons between the upper and lower cortical layers for 30-34 or 35-40 gw infants ( $p=0.25$ and $p=0.55$, respectively).

To assess the effect of prematurity, we compared between more premature and less premature infants for 2 sets of neonates: PMA 33 (preterm) and $39 \mathrm{gw}$ (near term). Among 33 week PMA infants, $\mathrm{GAD} 7^{+}$cells were fewer in $26-27 \mathrm{gw}$ infants (more premature) compared with $32-33$ gw preterm infants (less premature) in the upper cortical layer $(p=0.03)$, but not in the lower cortical layer ( $p=0.32$; Fig. $4 A, B)$. There was no difference in the density of GAD $67^{+}$cells between more and less premature infants for 39 postmenstrual week (near-term) infants in the upper or lower cortical layers $(p=0.34$ and $p=0.75$ in upper and lower layers, respectively; Fig. $4 C$ ). We conclude that premature birth reduces $\mathrm{GAD} 7^{+}$interneurons in the upper cortical layers, which is consistent with a similar reduction in $\mathrm{PV}^{+}$cells.

\section{Estrogen treatment increases the density of $\mathrm{PV}^{+}$ interneurons in preterm rabbits}

Because premature birth decreases the estrogen level 100-fold (Trotter and Pohlandt, 2000) and because a reduction in estrogen level in adolescent mice with oophorectomy diminishes the density of $\mathrm{PV}^{+}$interneurons (Corvino et al., 2015), we postulated that estrogen treatment might increase the $\mathrm{PV}^{+}$population in prematurely delivered rabbits. To investigate this, we sequentially treated preterm rabbits (E28.5) with $17 \beta$-estradiol and stereologically quantified the number of $\mathrm{PV}^{+}$cells in both upper and 
A

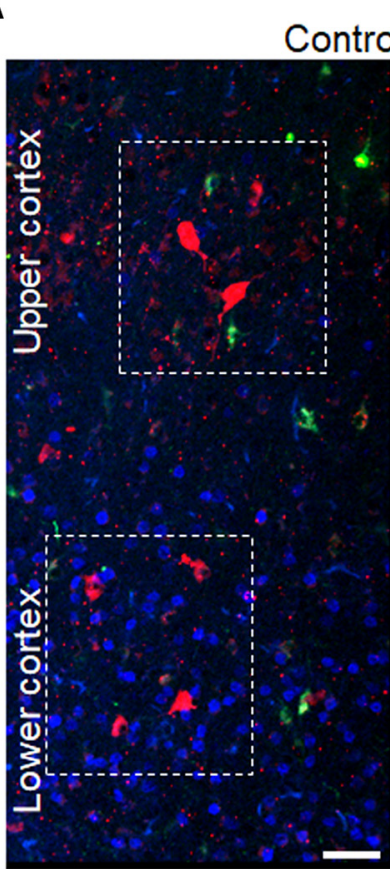

(D14) PV SST TLE4 E2 (D14)
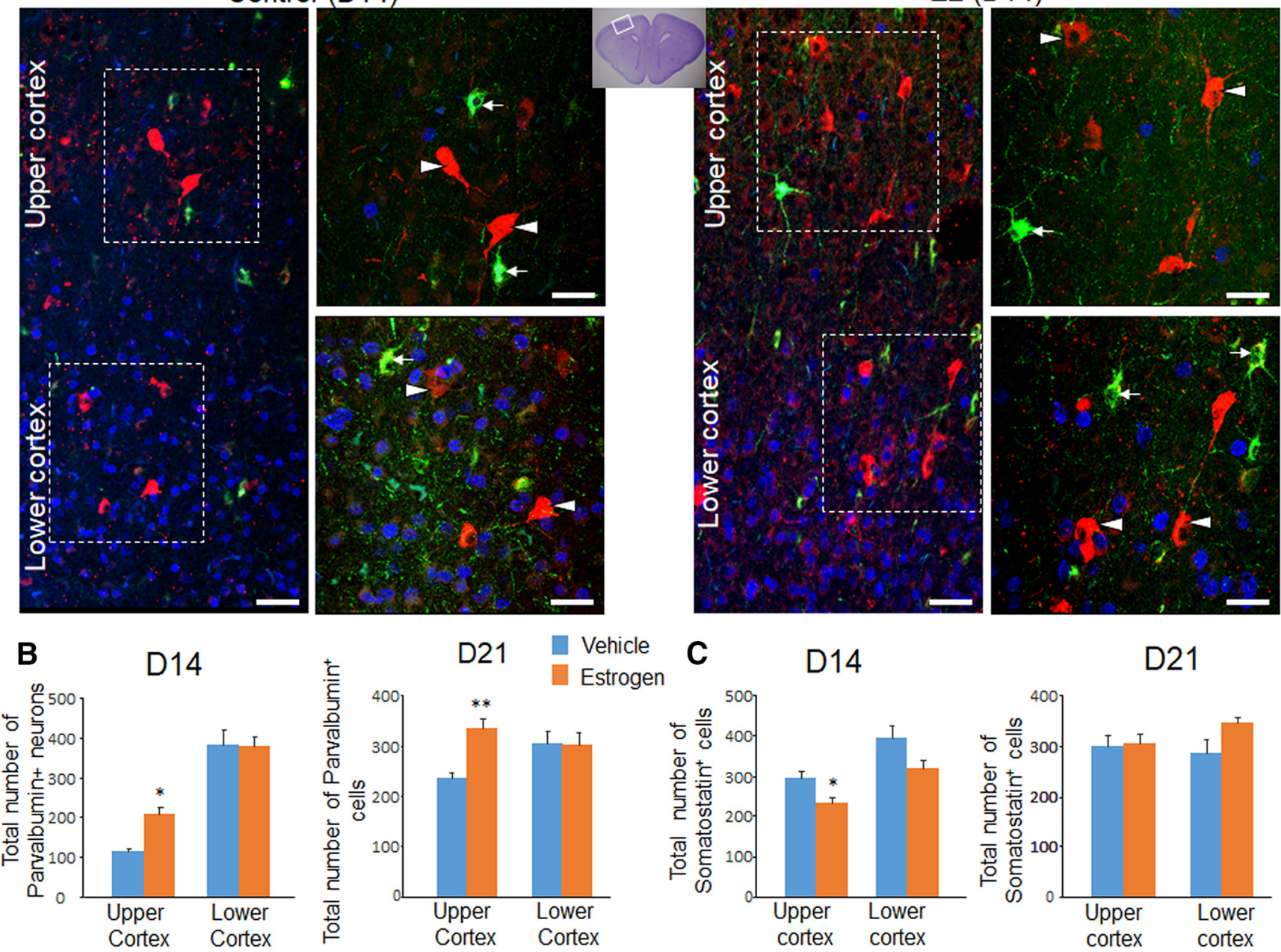

C

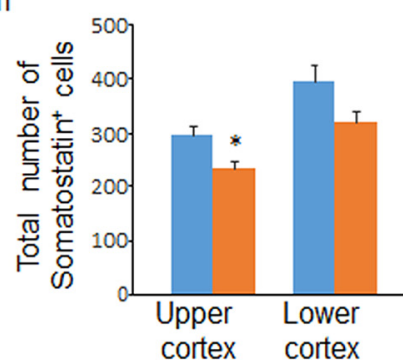

D21

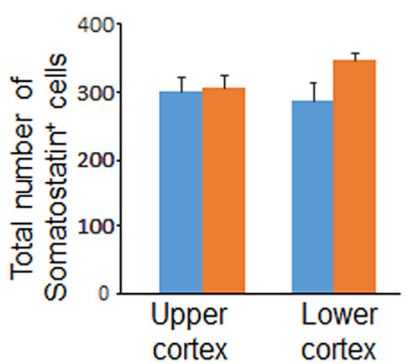

Figure 5. Effect of estrogen on the density of $\mathrm{PV}^{+}$and SST ${ }^{+}$interneurons. $A$, Representative immunofluorescence of cryosections of estrogen- (E2) and vehicle-treated kits labeled with SSTPV-, and TLE4-specific antibodies at P14. The lower cortical layer shows expression of TLE4 ${ }^{+}$(blue) cells, which are relatively absent in the upper cortical layer. The panels on the right are high-power views of the boxed areas on the left. Note higher number of $\mathrm{PV}^{+}$cells (arrowhead) in E2-treated kits compared with controls. SST ${ }^{+}$cells (arrow) are in both upper and lower cortical layers. Scale bar, $50 \mu \mathrm{m} . \boldsymbol{B}$, Data are shown as mean \pm SEM $\left(n=5\right.$ each group). Stereological quantification show that the number of PV ${ }^{+}$cells is greater in the E2-treated kits compared with controls in the upper cortical layer at both P14 and P21, but similar for the lower cortical layer. C, Data are shown as mean \pm SEM ( $n=5$ each group). Stereological quantification shows that the total number of $\mathrm{SST}^{+}$cells is reduced in E2-treated kits relative to and vehicle controls in upper cortical layer at day 14 , but not at day $21 .{ }^{*} p<0.05,{ }^{* *} p<0.01$ for estrogen- versus vehicle-treated kits. Boxed area in the cresyl violet-stained image depicts brain region in the coronal section where cells were quantified. Upper cortex, Upper cortical layer; lower cortex, lower cortical layer.

lower cortical layers of cortex at P14 and P21 (Fig. 5). The kits were balanced with respect to sex in the two groups, which was determined by performing qRT-PCR for the SRY gene. We noted that the number of $\mathrm{PV}^{+}$cells in the upper cortical layer was higher in $17 \beta$-estradiol-treated rabbits compared with vehicle controls at both P14 and P21 ( $p=0.014$ and $p=0.005$, respectively). This difference, however, was not observed in the lower cortical layers ( $p=0.7$ and $p=0.9$, respectively). In contrast to $\mathrm{PV}$, the number of SST ${ }^{+}$cells was reduced in $17 \beta$-estradioltreated kits relative to controls $(p=0.03)$ at $\mathrm{P} 14$ in the upper cortical layer, but not in the lower cortical layer $(p=0.08)$. However, there was no significant difference in the number of $\mathrm{SST}^{+}$cells between $17 \beta$-estradiol- and vehicle-treated kits at P21 for upper or lower cortical layers ( $p=0.8$ and $p=0.1$, upper and lower layer, respectively). We conclude that $17 \beta$-estradiol treatment increases the PV population at both P14 and P21 and reduces SST population transiently at P14 in the upper cortical layer of premature rabbits.
Estrogen treatment increases Arx expression on interneuron progenitors in preterm rabbits

Arx, Sox6, and Lhx6 promote tangential migration and maturation of interneurons (Vogt et al., 2014) and estradiol treatment alters the transcription of Arx and its downstream target (Olivetti et al., 2014). Therefore, we quantified the protein and mRNA levels of these transcription factors. We found that $17 \beta$-estradiol treatment increased mRNA expression of Arx at both P3 and P7 ( $p=0.048$ and 0.049 , respectively; Fig. $6 A$ ). Accordingly Arx protein levels, measured by Western blot analyses, were elevated at P14 in $17 \beta$-estradiol-treated kits compared with vehicle controls $(p=0.013)$, but not at $\mathrm{P} 3$ and $\mathrm{P} 7(p=0.12$ and $p=0.2$, respectively; Fig. $6 B, C$ ). Lhx6 and Sox6 mRNA levels were comparable between $17 \beta$-estradiol- and vehicle-treated kits (data not shown).

Arx modulates expression of Lmo3, Shox2, and CXCR4 (Fulp et al., 2008), so we also quantified their expression. Lmo3 protein expression was reduced in $17 \beta$-estradiol-treated rabbits com- 
A

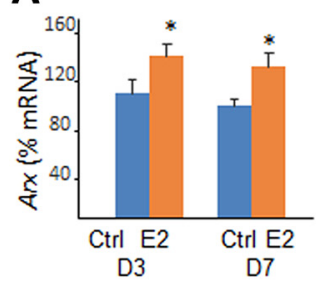

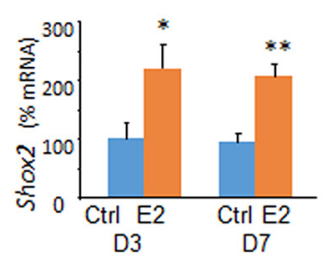

D3

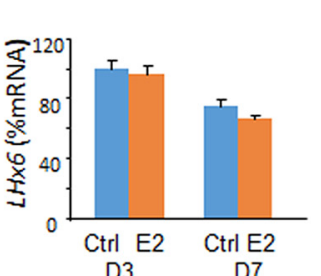

D3

志
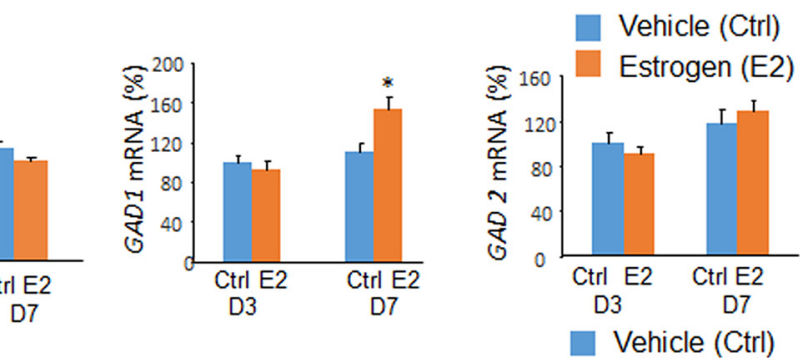

$\square$ Vehicle (Ctrl)

Estrogen (E2)
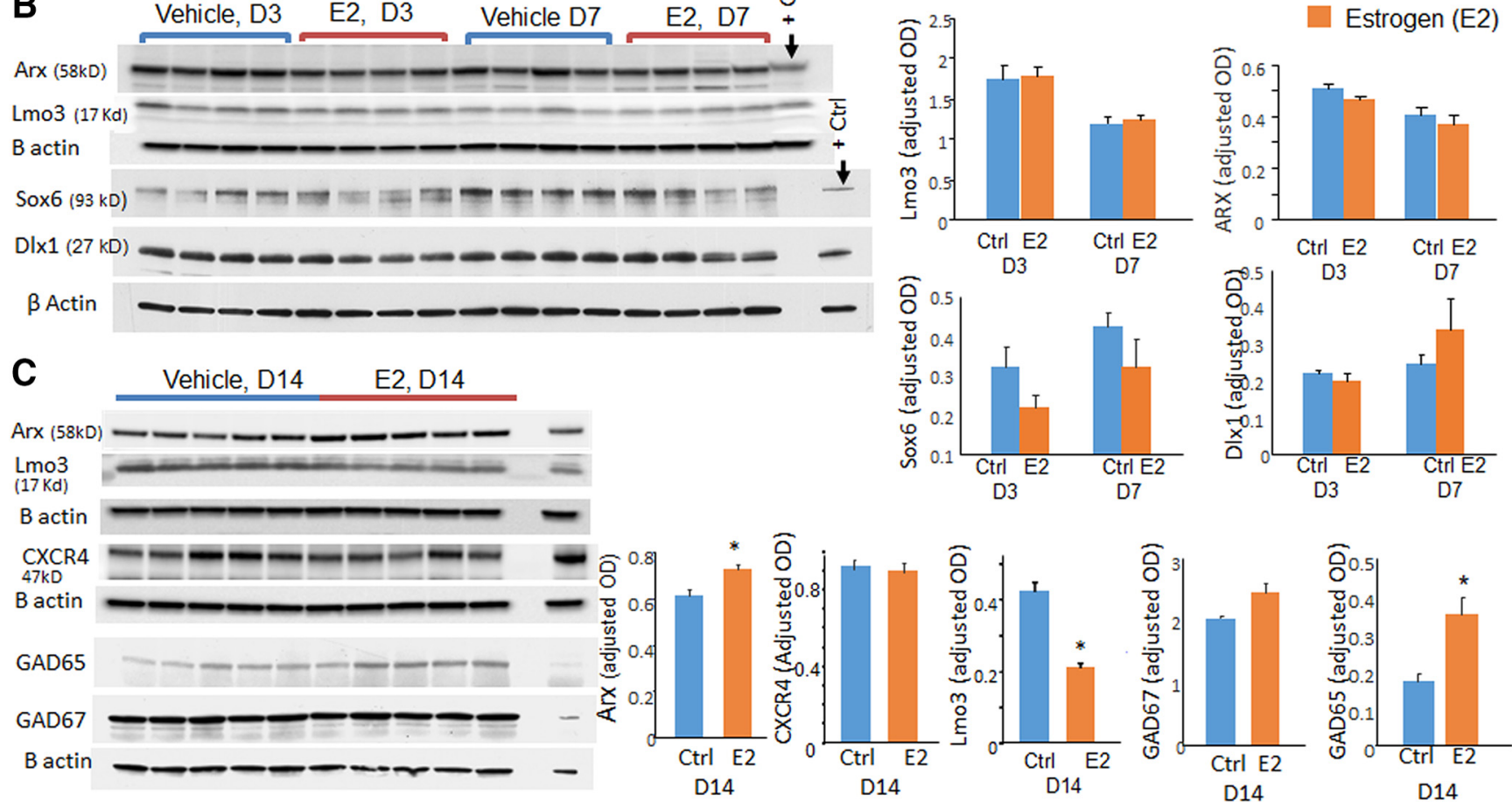

Figure 6. Estrogen (E2) treatment elevates Arx, Shox2, and Gad65/67 levels. A, Data are shown as mean \pm SEM ( $n=5$ each group). mRNA expression of Arx, Shox2, and Gad1 was higher in E2-treated kits relative to controls as indicted. GAD2 and Lhx6 were comparable between the two groups. $\boldsymbol{B}$, Representative Western blot analyses for Arx, Lm03, Sox6, and Dlx1 in brain homogenates from E2-and vehicle-treated kits at P3 and P7. Data are shown as mean \pm SEM ( $n=5$ each group). The protein levels were comparable between E2-treated kits relative to controls at both P3 and P7. C, Representative Western blot analyses for Arx, Lm03, CXCR4, Gad65, and Gad67 in brain homogenates from E2- and vehicle-treated kits at P14. Data are shown as mean \pm SEM ( $n=5$ each group). Arx and GAD65 protein level was higher in E2-treated kits relative to controls at P14, whereas $\mathrm{Lm} 03$ was reduced in E2-treated kits compared with controls. ${ }^{*} p<0.05$, ${ }^{* *} p<$ 0.01 for E2- versus vehicle-treated kits.

pared with vehicle controls at P14 ( $p<0.01$; Fig. $6 C)$. Shox2 mRNA expression was increased after $17 \beta$-estradiol treatment at both P3 and P7 ( $p=0.008$ and $p=0.012$, respectively; Fig. $6 A$ ). We could not assess Shox 2 protein levels by Western blot analyses in the absence of a reliable commercially available Shox 2 antibody reactive to rabbits. $17 \beta$-estradiol treatment did not affect Cxcr4 protein levels at P3, P7, or P14 ( $p=0.3$; data for P3 and P7 not shown). We also found elevation in GAD67 gene transcription at $\mathrm{P} 7(p=0.008)$ and GAD65 protein levels at $\mathrm{P} 14(p=$ 0.01 ) in $17 \beta$-estradiol-treated rabbits compared with controls, which would indicate maturation of interneurons upon 17 $\beta$-estradiol treatment. Therefore, $17 \beta$-estradiol treatment increased Arx expression and also changed levels of its downstream molecules Shox2 and Lmo3, which was consistent with previous studies (Olivetti et al., 2014).

Because the Arx protein level was elevated in $17 \beta$-estradioltreated pups compared with vehicle controls at P14, we next evaluated Arx expression on interneuron progenitors in immunolabeled sections in these two groups of kits. To this end, we double labeled coronal sections from the forebrain with Arx- and Dlx2-specific antibody (Fig. 7). We assessed Dlx2 and Arx immunoreactivity in the ventral SVZ along the lateral wall, which is a remnant of lateral ganglionic eminence and in the adjacent white matter. We observed an overall increased immunoreactivity for Arx in these regions in $17 \beta$-estradiol-treated kits compared with vehicle controls at P14. We next quantified Dlx ${ }^{+} \mathrm{Arx}^{+}$cells in the ventral SVZ and adjacent white matter and found that Dlx2and Arx-colabeled cells were more abundant in $17 \beta$-estradioltreated pups relative to vehicle controls at P14 $(p<0.001$, unpaired $t$ test; Fig. 7).

Our results show that $17 \beta$-estradiol treatment upregulates Arx expression and downregulates its gene target, Lmo3, which could contribute to increased maturation and migration of interneurons, resulting in their increased number in the cerebral cortex.

\section{Discussion}

Preterm birth and its associated morbidity is a global public health problem. Approximately $11 \%$ of infants are born prematurely and survivors often suffer from neurobehavioral complications during childhood and adolescence. These neuropsychiatric disorders might be attributed to defective structure and function of cortical interneurons. Herein, we explored how the cortical interneuron population evolves in the upper and lower cerebral cortical layers with increas- 
A

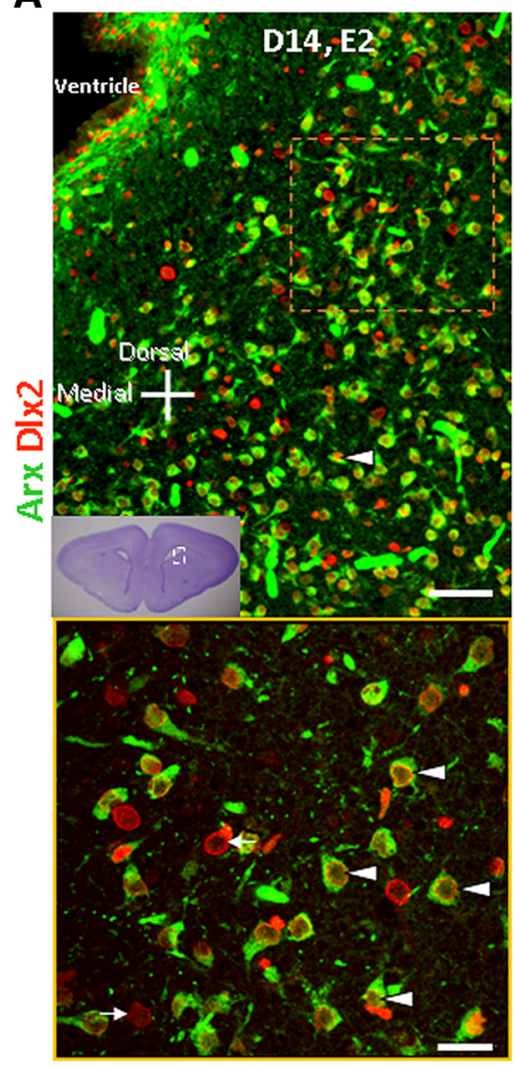

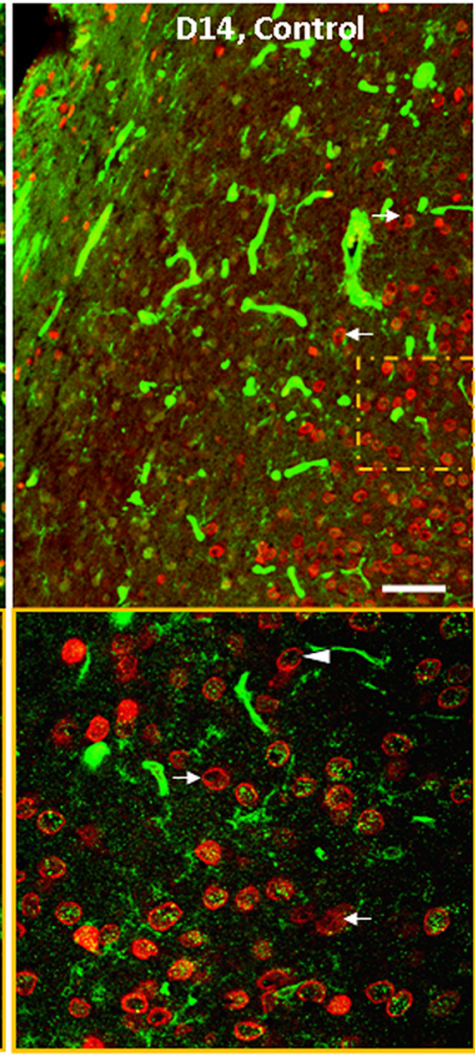

B

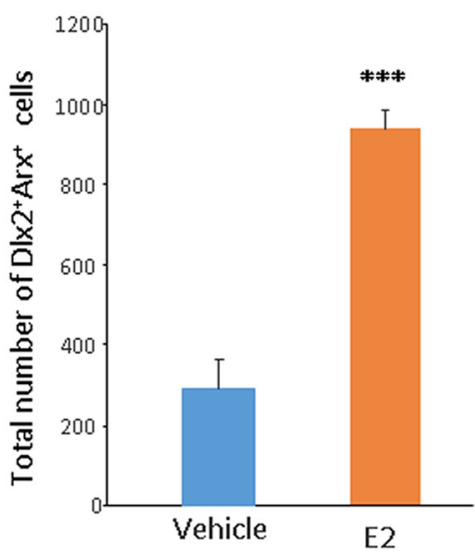

Figure 7. $17 \beta$ estradiol (E2) increases expression of Arx. $A$, Representative immunofluorescence of cryosections of E2- and vehicle-treated kits labeled with Arx- and Dlx2-specific antibodies at P14. Bottom is high-power view of the boxed area at the top. Note extensive colocalization of Dlx2 ${ }^{+}$cells with Arx expression (arrowhead). Arrows indicate those Dlx2 ${ }^{+}$cells that do not express Arx. Scale bars, $20 \mu \mathrm{m}$ (top), $50 \mu \mathrm{m}$ (bottom). B, Data are shown as mean \pm SEM $\left(n=5\right.$ each group). Arx ${ }^{+}$and Dlx ${ }^{+} \mathrm{Arx}^{+}$cells were more abundant in E2-treated kits relative to vehicle controls. $*^{* * *} p<0.01$ for E2-versus vehicle-treated kits.

ing gestational age and assessed the effect of prematurity on the heterogeneity of interneurons in the cerebral cortex. We found that cortical interneurons are progressively recruited in the cortical layers with advancing gestational age. Premature birth leads to deficits in the density of $\mathrm{PV}^{+}$and GAD67 ${ }^{+}$interneurons and abundance of $\mathrm{SST}^{+}$neurons in the upper cortical layers (II-IV) of human cerebral cortex. Additionally, we demonstrated that estrogen treatment increased the density of $\mathrm{PV}^{+}$interneurons in preterm rabbits and transiently reduced the population of $\mathrm{SST}^{+}$neurons. Furthermore, we noted that estrogen treatment increased the expression of Arx transcription factors, which might enhance migration and maturation of $\mathrm{PV}^{+}$interneurons into the cerebral cortex. Our results show that a withdrawal of maternal estrogen from premature birth might cause an altered PV/SST ratio, which can be reversed by estrogen replacement therapy.

The most important and novel observation made in this study was that premature birth led to reduced density of $\mathrm{PV}^{+}$interneurons and an excessive number of SST ${ }^{+}$interneurons. To our knowledge, this is the first demonstration of the impact of prematurity on the density of interneurons in the human cerebral cortex. This disruption in the population of interneuronal subtypes can be attributed to premature birth and/or to prematurity-related complications, including mild intraventricular hemorrhage (IVH), sepsis, necrotizing enterocolitis, and others. Because we excluded cases of moderate-to-severe IVH and hypoxic-ischemic encephalopathy we cannot ascribe these perturbations in the heterogeneity of interneurons to these two disorders. PV deficit has also been reported in neuropsychiatric conditions, including autism spectrum disorders (ASD), schizophrenia, and bipolar disorders (Berridge, 2013; Zikopoulos and Barbas, 2013; Stoner et al., 2014). In addition, a reduction in the number of $\mathrm{PV}^{+}$neurons $(\sim 20-25 \%)$ has been found in several genetic mouse models of ASD, in which the impact of the cntnap2, Met, Fmr1, Nign3, and Nrp2 genes on neurobehavior has been studied (Selby et al., 2007; Gogolla et al., 2009; Martins et al., 2011; Peñagarikano et al., 2011). Because $\mathrm{PV}^{+}$neurons are fastspiking neurons and have a high energy demand, the downregulation of PV has been postulated as an adoptive mechanism of the brain during adverse conditions (Lewis et al., 2005; Berridge, 2013). $\mathrm{PV}^{+}$neurons serve important functions: they play key roles in the production of gamma oscillations, delay short-term facilitation, and affect neuronal firing timings, thereby influencing desynchronization of neuronal networks in the cortex (Orduz et al., 2013). A reduction in number of $\mathrm{PV}^{+}$neurons results in reduced inhibitory control over pyramidal cell activity and diminished coordinated activity of the large brain network (Etherton et al., 2011). Therefore, a reduction in the number of $\mathrm{PV}^{+}$ neurons can be a maladaptive response of the brain to prematurity and its associated complications, which might contribute to the development of psychiatric and neurological symptoms in preterm-born children and adolescents. $\mathrm{SST}^{+}$interneurons generate $\beta$-frequency oscillations $(15-30 \mathrm{~Hz})$. They are less extensively studied compared with $\mathrm{PV}^{+}$neurons and, accordingly, the contribution of SST ${ }^{+}$neurons to cerebral function is less well understood. SST ${ }^{+}$interneurons are located within cortical networks to integrate unimodal or crossmodal sensory information 
processing (Marín, 2012). They are important mediators of experience-dependent plasticity and promote lifelong learning (Scheyltjens and Arckens, 2016). Together, a combination of excess $\mathrm{SST}^{+}$and dearth in $\mathrm{PV}^{+}$interneurons might cause neuropsychiatric manifestations in preterm-born children and adolescents.

Estrogen has been shown to regulate interneurons in the forebrain, hippocampus, and other parts of the brain. In a rat model of trimethyltin-induced hippocampal degeneration, estrogen treatment increased GAD67 and PV expression (Corvino et al., 2015). Ovariectomy in adolescent mice significantly reduces PV expression in the dorsal hippocampus, which has been prevented by $17 \beta$-estradiol replacement (Wu et al., 2014). Similarly, estrogen treatment promotes PV expression in the arcuate nucleus in female mice (Sotonyi et al., 2010). However, the effect of estrogen on the heterogeneity of $\mathrm{PV}^{+}$and SST ${ }^{+}$in the cerebral cortex in premature animals has not been studied. In the present study, we found that estrogen treatment led to an increase in the number of $\mathrm{PV}^{+}$interneurons and a transient reduction in the density of $\mathrm{SST}^{+}$interneurons in the upper cortical layer. This increased population of $\mathrm{PV}^{+}$neurons upon $17 \beta$-estradiol treatment could be because of their reduced death, increased migration, enhanced maturation, or an augmented expression of PV on the interneurons. Our previous studies have shown that $17 \beta$-estradiol treatment does not significantly affect apoptosis in preterm rabbits (Tibrewal et al., 2018). Therefore, we reasoned that estrogen treatment might promote maturation and migration of cortical interneurons by modulating transcription factors, including Arx, Lh6, and Sox6 (Vogt et al., 2014). We found that both mRNA and protein expression of Arx was elevated after $17 \beta$-estradiol treatment. In addition, protein levels of Lmo3, the downstream target of Arx, was reduced in $17 \beta$-estradiol-treated rabbits compared with vehicle controls. These findings were consistent with the previous studies in Arx mutant model of infantile spasms, in which $17 \beta$-estradiol treatment restored depleted interneuron population and altered mRNA expression of Arx targets including Lmo1 and Shox 2 and (Olivetti et al., 2014). Arx mutant mice exhibit abnormal interneuron migration and subtype differentiation (Fulp et al., 2008). Evaluation of Arx function by knock down or overexpression using in utero electroporation has reinforced the idea that Arx is cell autonomously required for interneuron migration (Friocourt et al., 2008). Sox6 and Lhx6 were not influenced significantly by $17 \beta$-estradiol treatment. We conclude that estrogen treatment increases the population of $\mathrm{PV}^{+}$ neurons, which might be attributed to Arx-induced escalation in interneuronal migration and differentiation.

Preterm birth decreases the level of plasma estrogen 100-fold (Trotter and Pohlandt, 2000). Indeed, replacement estrogen and progesterone treatment has undergone one small clinical trial in extremely premature infants and have shown marginal benefit with respect to improved lung maturation, better bone mineral accretion rate, and lower incidence of chronic lung disease (Khosla et al., 1981; Trotter et al., 1999; Hunt et al., 2004). Moreover, estrogen treatment alleviates white matter injury in models of hypoxia-ischemia and hyperoxia, protects immature neurons and astroglia, and promotes synapse formation (Hilton et al., 2006; Gerstner et al., 2007, 2009; Nuñez et al., 2007; McCarthy, 2008). These links reinforce the importance of estrogen treatment in promoting the growth and development of premature infants. In the present study, we have not evaluated the effect of estrogen on neurobehavioral function of kits. A future study showing improved functional outcome of estrogen-supplemented premature rabbits will reinforce results of our present morphological and molecular studies.

The development of cortical interneurons in the cerebral cortex has been evaluated in human fetuses in the first and second trimester (Rakic and Zecevic, 2003; Jakovcevski et al., 2011). Herein, we made a number of important observations. First, $\mathrm{PV}^{+}$ cells were weakly immunoreactive and were difficult to identify in $<20$ gw and these cells progressively increased in density, almost doubling in number in preterm infants of $>28$ gw compared with $<28$ gw. Second, $\mathrm{PV}^{+}$cells in $20-40$ gw infants were the most abundant interneurons in the cortical layers and were severalfold greater in number compared with $\mathrm{SST}^{+}$cells. Third, $\mathrm{PV}^{+}$ cells were similar in density in upper and lower cortical layers; however, $\mathrm{SST}^{+}$cells were higher in number in the lower relative to upper cortical layers. Fourth, of the two CGE-derived interneurons, $\mathrm{CalR}^{+}$cells outnumbered $\mathrm{NPY}^{+}$interneurons in the cerebral cortex and $\mathrm{CalR}^{+}$interneurons were more abundant in the upper cortical layers and $\mathrm{NPY}^{+}$in the lower cortical layers. During late gestation, $\mathrm{PV}^{+}$cells are the predominant type of cortical interneuron arising from MGE and $\mathrm{CalR}^{+}$cells are the principal type of cortical interneuron arising from CGE. The development of $\mathrm{PV}^{+}$ cells in the cerebral cortex has been described to have inside-out maturation in rodents (Cao et al., 1996; Jakovcevski et al., 2011) and the cells are located in the infragranular layer at the earliest stages and absent in the overlying cortex. However, in humans, we found that $\mathrm{PV}^{+}$neurons were similar in density in upper and lower cortical layers. The preponderance of CalR ${ }^{+}$cells in the upper cortical layers in the present study is consistent with the data in rodents, human fetuses (8-17 gw), and adults (Casarosa et al., 1999; Rakic and Zecevic, 2003; Long et al., 2009; Radonjić et al., 2014). Lack of effect of prematurity on CalR density suggests that these subtypes of interneurons are more resistant to the insults of prematurity and related complications.

In conclusion, PV and CalR are the principle types of interneurons in the second half of human gestation and premature birth leads to a deficit of $\mathrm{PV}^{+}$and surplus in $\mathrm{SST}^{+}$interneurons in the upper cortical layers of human preterm infants. Estrogen treatment in preterm rabbits increases the density of $\mathrm{PV}^{+}$interneurons and temporarily reduces $\mathrm{SST}^{+}$interneurons in the upper cortical layers with an associated elevation in the expression of Arx transcription factor. It is plausible that a withdrawal of maternal estrogen after preterm birth contributes to PV deficit and SST excess in preterm infants and that estrogen treatment restores this altered ratio of $\mathrm{PV} / \mathrm{SST}^{+}$interneurons in premature infants.

\section{References}

Amantea D, Russo R, Bagetta G, Corasaniti MT (2005) From clinical evidence to molecular mechanisms underlying neuroprotection afforded by estrogens. Pharmacol Res 52:119-132. CrossRef Medline

Anderson P, Doyle LW; Victorian Infant Collaborative Study Group (2003) Neurobehavioral outcomes of school-age children born extremely low birth weight or very preterm in the 1990s. JAMA 289:3264-3272. CrossRef Medline

Anderson PJ, Doyle LW; Victorian Infant Collaborative Study Group (2004) Executive functioning in school-aged children who were born very preterm or with extremely low birth weight in the 1990s. Pediatrics 114:50 57. CrossRef Medline

Arshad A, Vose LR, Vinukonda G, Hu F, Yoshikawa K, Csiszar A, Brumberg JC, Ballabh P (2016) Extended production of cortical interneurons into the third trimester of human gestation. Cereb Cortex 26:2242-2256. CrossRef Medline

Ballabh P, Xu H, Hu F, Braun A, Smith K, Rivera A, Lou N, Ungvari Z, Goldman SA, Csiszar A, Nedergaard M (2007) Angiogenic inhibition reduces germinal matrix hemorrhage. Nat Med 13:477-485. CrossRef Medline 
Berridge MJ (2013) Dysregulation of neural calcium signaling in alzheimer disease, bipolar disorder and schizophrenia. Prion 7:2-13. CrossRef Medline

Botting N, Powls A, Cooke RW, Marlow N (1997) Attention deficit hyperactivity disorders and other psychiatric outcomes in very low birthweight children at 12 years. J Child Psychol Psychiatry 38:931-941. CrossRef Medline

Brinton RD (2009) Estrogen-induced plasticity from cells to circuits: predictions for cognitive function. Trends Pharmacol Sci 30:212-222. CrossRef Medline

Cao QL, Yan XX, Luo XG, Garey LJ (1996) Prenatal development of parvalbumin immunoreactivity in the human striate cortex. Cereb Cortex 6:620-630. CrossRef Medline

Casarosa S, Fode C, Guillemot F (1999) Mash1 regulates neurogenesis in the ventral telencephalon. Development 126:525-534. Medline

Colasante G, Collombat P, Raimondi V, Bonanomi D, Ferrai C, Maira M, Yoshikawa K, Mansouri A, Valtorta F, Rubenstein JL, Broccoli V (2008) Arx is a direct target of Dlx2 and thereby contributes to the tangential migration of GABAergic interneurons. J Neurosci 28:10674-10686. CrossRef Medline

Corvino V, Di Maria V, Marchese E, Lattanzi W, Biamonte F, Michetti F, Geloso MC (2015) Estrogen administration modulates hippocampal GABAergic subpopulations in the hippocampus of trimethyltin-treated rats. Front Cell Neurosci 9:433. CrossRef Medline

de Kieviet JF, van Elburg RM, Lafeber HN, Oosterlaan J (2012) Attention problems of very preterm children compared with age-matched term controls at school-age. J Pediatr 161:824-829 e821. CrossRef Medline

Delobel-Ayoub M, Arnaud C, White-Koning M, Casper C, Pierrat V, Garel M, Burguet A, Roze JC, Matis J, Picaud JC, Kaminski M, Larroque B; EPIPAGE Study Group (2009) Behavioral problems and cognitive performance at 5 years of age after very preterm birth: the EPIPAGE study. Pediatrics 123:1485-1492. CrossRef Medline

Etherton M, Földy C, Sharma M, Tabuchi K, Liu X, Shamloo M, Malenka RC, Südhof TC (2011) Autism-linked neuroligin-3 R451C mutation differentially alters hippocampal and cortical synaptic function. Proc Natl Acad Sci U S A 108:13764-13769. CrossRef Medline

Friocourt G, Kanatani S, Tabata H, Yozu M, Takahashi T, Antypa M, Raguénès $\mathrm{O}$, Chelly J, Férec $\mathrm{C}$, Nakajima K, Parnavelas JG (2008) Cellautonomous roles of ARX in cell proliferation and neuronal migration during corticogenesis. J Neurosci 28:5794-5805. CrossRef Medline

Fulp CT, Cho G, Marsh ED, Nasrallah IM, Labosky PA, Golden JA (2008) Identification of arx transcriptional targets in the developing basal forebrain. Hum Mol Genet 17:3740-3760. CrossRef Medline

Gerstner B, Lee J, DeSilva TM, Jensen FE, Volpe JJ, Rosenberg PA (2009) 17beta-estradiol protects against hypoxic/ischemic white matter damage in the neonatal rat brain. J Neurosci Res 87:2078-2086. CrossRef Medline

Gerstner B, Sifringer M, Dzietko M, Schüller A, Lee J, Simons S, Obladen M, Volpe JJ, Rosenberg PA, Felderhoff-Mueser U (2007) estradiol attenuates hyperoxia-induced cell death in the developing white matter. Ann Neurol 61:562-573. CrossRef Medline

Gogolla N, Leblanc JJ, Quast KB, Südhof TC, Fagiolini M, Hensch TK (2009) Common circuit defect of excitatory-inhibitory balance in mouse models of autism. J Neurodev Disord 1:172-181. CrossRef Medline

Hevner RF (2007) Layer-specific markers as probes for neuron type identity in human neocortex and malformations of cortical development. J Neuropathol Exp Neurol 66:101-109. CrossRef Medline

Hilton GD, Bambrick LL, Thompson SM, McCarthy MM (2006) estradiol modulation of kainic acid-induced calcium elevation in neonatal hippocampal neurons. Endocrinology 147:1246-1255. CrossRef Medline

Hunt R, Davis PG, Inder T (2004) Replacement of estrogens and progestins to prevent morbidity and mortality in preterm infants. Cochrane Database Syst Rev 4:CD003848. CrossRef Medline

Indredavik MS, Vik T, Evensen KA, Skranes J, Taraldsen G, Brubakk AM (2010) Perinatal risk and psychiatric outcome in adolescents born preterm with very low birth weight or term small for gestational age. J Dev Behav Pediatr 31:286-294. CrossRef Medline

Jakovcevski I, Mayer N, Zecevic N (2011) Multiple origins of human neocortical interneurons are supported by distinct expression of transcription factors. Cereb Cortex 21:1771-1782. CrossRef Medline

Kepecs A, Fishell G (2014) Interneuron cell types are fit to function. Nature 505:318-326. CrossRef Medline

Khosla SS, Smith GJ, Parks PA, Rooney SA (1981) Effects of estrogen on fetal rabbit lung maturation: morphological and biochemical studies. Pediatr Res 15:1274-1281. CrossRef Medline

Letinic K, Kostovic I (1998) Postnatal development of calcium-binding proteins calbindin and parvalbumin in human visual cortex. Cereb Cortex 8:660-669. CrossRef Medline

Lewis DA, Hashimoto T, Volk DW (2005) Cortical inhibitory neurons and schizophrenia. Nat Rev Neurosci 6:312-324. CrossRef Medline

Long JE, Cobos I, Potter GB, Rubenstein JL (2009) Dlx1\&2 and Mash1 transcription factors control MGE and CGE patterning and differentiation through parallel and overlapping pathways. Cereb Cortex 19:i96-i106. CrossRef Medline

Malik S, Vinukonda G, Vose LR, Diamond D, Bhimavarapu BB, Hu F, Zia MT, Hevner R, Zecevic N, Ballabh P (2013) Neurogenesis continues in the third trimester of pregnancy and is suppressed by premature birth. J Neurosci 33:411-423. CrossRef Medline

Marín O (2012) Interneuron dysfunction in psychiatric disorders. Nat Rev Neurosci 13:107-120. CrossRef Medline

Marsh ED, Nasrallah MP, Walsh C, Murray KA, Nicole Sunnen C, McCoy A, Golden JA (2016) Developmental interneuron subtype deficits after targeted loss of arx. BMC Neurosci 17:35. CrossRef Medline

Martins GJ, Shahrokh M, Powell EM (2011) Genetic disruption of met signaling impairs GABAergic striatal development and cognition. Neuroscience 176:199-209. CrossRef Medline

McCarthy MM (2008) estradiol and the developing brain. Physiol Rev 88: 91-124. CrossRef Medline

Miyoshi G, Fishell G (2011) GABAergic interneuron lineages selectively sort into specific cortical layers during early postnatal development. Cereb Cortex 21:845-852. CrossRef Medline

Nuñez J, Yang Z, Jiang Y, Grandys T, Mark I, Levison SW (2007) 17betaestradiol protects the neonatal brain from hypoxia-ischemia. Exp Neurol 208:269-276. CrossRef Medline

Olivetti PR, Maheshwari A, Noebels JL (2014) Neonatal estradiol stimulation prevents epilepsy in Arx model of X-linked infantile spasms syndrome. Sci Transl Med 6:220ra212. CrossRef Medline

Orduz D, Bischop DP, Schwaller B, Schiffmann SN, Gall D (2013) Parvalbumin tunes spike-timing and efferent short-term plasticity in striatal fast spiking interneurons. J Physiol 591:3215-3232. CrossRef Medline

Peñagarikano O, Abrahams BS, Herman EI, Winden KD, Gdalyahu A, Dong H, Sonnenblick LI, Gruver R, Almajano J, Bragin A, Golshani P, Trachtenberg JT, Peles E, Geschwind DH (2011) Absence of CNTNAP2 leads to epilepsy, neuronal migration abnormalities, and core autismrelated deficits. Cell 147:235-246. CrossRef Medline

Picazo O, Azcoitia I, Garcia-Segura LM (2003) Neuroprotective and neurotoxic effects of estrogens. Brain Res 990:20-27. CrossRef Medline

Radonjić NV, Ortega JA, Memi F, Dionne K, Jakovcevski I, Zecevic N (2014) The complexity of the calretinin-expressing progenitors in the human cerebral cortex. Front Neuroanat 8:82. CrossRef Medline

Rakic S, Zecevic N (2003) Emerging complexity of layer I in human cerebral cortex. Cereb Cortex 13:1072-1083. CrossRef Medline

Rymar VV, Sadikot AF (2007) Laminar fate of cortical GABAergic interneurons is dependent on both birthdate and phenotype. J Comp Neurol 501:369-380. CrossRef Medline

Scheyltjens I, Arckens L (2016) The current status of somatostatininterneurons in inhibitory control of brain function and plasticity. Neural Plast 2016:8723623. CrossRef Medline

Selby L, Zhang C, Sun QQ (2007) Major defects in neocortical GABAergic inhibitory circuits in mice lacking the fragile $\mathrm{X}$ mental retardation protein. Neurosci Lett 412:227-232. CrossRef Medline

Sotonyi P, Gao Q, Bechmann I, Horvath TL (2010) Estrogen promotes parvalbumin expression in arcuate nucleus POMC neurons. Reprod Sci 17:1077-1080. CrossRef Medline

Stoner R, Chow ML, Boyle MP, Sunkin SM, Mouton PR, Roy S, WynshawBoris A, Colamarino SA, Lein ES, Courchesne E (2014) Patches of disorganization in the neocortex of children with autism. N Engl J Med 370:1209-1219. CrossRef Medline

Tibrewal M, Cheng B, Dohare P, Hu F, Mehdizadeh R, Wang P, Zheng D, Ungvari Z, Ballabh P (2018) Disruption of interneuron neurogenesis in premature newborns and reversal with estrogen treatment. J Neurosci 38:1100-1113. CrossRef Medline

Trotter A, Pohlandt F (2000) The replacement of oestradiol and progesterone in very premature infants. Ann Med 32:608-614. CrossRef Medline 
Trotter A, Maier L, Grill HJ, Kohn T, Heckmann M, Pohlandt F (1999) Effects of postnatal estradiol and progesterone replacement in extremely preterm infants. J Clin Endocrinol Metab 84:4531-4535. CrossRef Medline

Twining RC, Tuscher JJ, Doncheck EM, Frick KM, Mueller D (2013) 17beta-estradiol is necessary for extinction of cocaine seeking in female rats. Learn Mem 20:300-306. CrossRef Medline

Vinukonda G, Hu F, Mehdizadeh R, Dohare P, Kidwai A, Juneja A, Naran V, Kierstead M, Chawla R, Kayton R, Ballabh P (2016) Epidermal growth factor preserves myelin and promotes astrogliosis after intraventricular hemorrhage. Glia 64:1987-2004. CrossRef Medline

Vogt D, Hunt RF, Mandal S, Sandberg M, Silberberg SN, Nagasawa T, Yang Z, Baraban SC, Rubenstein JL (2014) Lhx6 directly regulates arx and
CXCR7 to determine cortical interneuron fate and laminar position. Neuron 82:350-364. CrossRef Medline

Wonders CP, Anderson SA (2006) The origin and specification of cortical interneurons. Nat Rev Neurosci 7:687-696. CrossRef Medline

Wu YC, Du X, van den Buuse M, Hill RA (2014) Sex differences in the adolescent developmental trajectory of parvalbumin interneurons in the hippocampus: a role for estradiol. Psychoneuroendocrinology 45:167178. CrossRef Medline

Zecevic N, Hu F, Jakovcevski I (2011) Interneurons in the developing human neocortex. Dev Neurobiol 71:18-33. CrossRef Medline

Zikopoulos B, Barbas H (2013) Altered neural connectivity in excitatory and inhibitory cortical circuits in autism. Front Hum Neurosci 7:609. CrossRef Medline 